ARTICLE

https://doi.org/10.1038/s41467-021-24047-2

\title{
OPEN
}

\section{Inhibition of MRN activity by a telomere protein motif}

Freddy Khayat1,6, Elda Cannavo 2,6, Majedh Alshmery', William R. Foster', Charly Chahwan (10) 1,4 Martino Maddalena ${ }^{1,5}$, Christopher Smith (1) ${ }^{1}$, Antony W. Oliver (1) ${ }^{1}$, Adam T. Watson ${ }^{1}$, Antony M. Carr (1) ${ }^{1}$, Petr Cejka ${ }^{2,3} \&$ Alessandro Bianchi (i) ${ }^{1 凶}$

The MRN complex (MRX in Saccharomyces cerevisiae, made of Mre11, Rad50 and Nbs1/Xrs2) initiates double-stranded DNA break repair and activates the Tel1/ATM kinase in the DNA damage response. Telomeres counter both outcomes at chromosome ends, partly by keeping MRN-ATM in check. We show that MRX is disabled by telomeric protein Rif2 through an Nterminal motif (MIN, MRN/X-inhibitory motif). MIN executes suppression of Tel1, DNA endresection and non-homologous end joining by binding the Rad50 N-terminal region. Our data suggest that MIN promotes a transition within MRX that is not conductive for endonuclease activity, DNA-end tethering or Tel1 kinase activation, highlighting an Achilles' heel in MRN, which we propose is also exploited by the RIF2 paralog ORC4 (Origin Recognition Complex 4) in Kluyveromyces lactis and the Schizosaccharomyces pombe telomeric factor Taz1, which is evolutionarily unrelated to Orc4/Rif2. This raises the possibility that analogous mechanisms might be deployed in other eukaryotes as well.

\footnotetext{
${ }^{1}$ Genome Damage and Stability Centre, School of Life Sciences, University of Sussex, Brighton, UK. ${ }^{2}$ Institute for Research in Biomedicine, Faculty of Biomedical Sciences, Università della Svizzera italiana (USI), Bellinzona, Switzerland. ${ }^{3}$ Department of Biology, Institute of Biochemistry, Eidgenössische Technische Hochschule (ETH), Zürich, Switzerland. ${ }^{4}$ Present address: SyntheX, Inc., San Francisco, CA, USA. ${ }^{5}$ Present address: Department of Molecular Cell Biology, Weizmann Institute of Science, Rehovot, Israel. ${ }^{6}$ These authors contributed equally: Freddy Khayat, Elda Cannavo. ${ }^{凶}$ email: a.bianchi@sussex.ac.uk
} 
T elomeres make a crucial contribution to genome stability by ensuring both the full replication of chromosome ends, through the action of the telomerase enzyme (reviewed in ref. ${ }^{1}$ ), and their protection, through the agency of the telomeric complex (shelterin in vertebrates, reviewed in ref. ${ }^{2}$ ). Telomerase synthesises short DNA repeats onto chromosome ends, which serve as a platform for the binding of telomere-specific and accessory factors. These factors, in turn, modulate the activity of the telomerase enzyme, and the feedback at each telomere determines the ultimate length of the telomeric DNA repeat array, which is mostly present in double-stranded form but terminates in a single-stranded $3^{\prime}$ overhang. Although it was early on predicted that telomeres would need to be equipped with mechanisms to disable the various arms of the DNA damage response (DDR) machinery, it was perhaps unanticipated that several of the DDR factors would be instrumental in ensuring telomere end processing and telomerase activity, as first documented in budding and fission yeast ${ }^{3-6}$. While several differences in the way the telomeric complex interacts with and affects DDR factors in different organisms are well documented, several common themes have emerged (reviewed in refs. ${ }^{7,8}$ ). An example where elements of the DDR have been co-opted for telomere function is in the activation of telomerase. In the budding yeast Saccharomyces cerevisiae, the MRX complex, which is composed of Mre11, Rad50 and Xrs2 (Nbs1 in most other organisms) and is responsible for the recruitment/activation of the DDR kinase Tel1 (the ATM ortholog in yeast), promotes telomerase action: ablation of any of the three subunits, or of Tell, leads to dramatic telomere shortening ${ }^{3,9,10}$. Similar requirements for the Tel1/ATM or the ATR ( $\operatorname{Rad} 3$ in fission yeast) kinase for telomerase activation take place in mammalian cells and in fission yeast ${ }^{11-13}$.

The MRN complex is instrumental in orchestrating both DDR signalling and DNA repair, and acts as the main sensor of doublestrand breaks (DSBs) ${ }^{14}$. The complex is equipped with nuclease and ATPase activity by Mre11 and Rad50 subunits, respectively, and has some structural similarity to the SMC family of proteins, with elongated coiled-coil (CC) motifs from the Rad50 subunits, which fold back onto themselves at a Zn hook formed at a CXXC motif found at the centre of the coiled region in Rad50. At the base of the CC region, a globular domain is formed where ATPbinding cassettes from two molecules of Rad50 come together and join an Mre11 dimer, in a tetrameric assembly. Nbs1/Xrs2 contains several protein interaction modules and is responsible for binding the Tel1/ATM kinase ${ }^{15-17}$. ATP binding and hydrolysis by Rad50 lead to conformational changes within the complex, and it has been proposed that the transition from an ATP-bound 'closed' complex to an 'open' one after ATP hydrolysis regulates the multiple activities of $\mathrm{MRN}^{18-21}$. The ATPbound 'closed' complex is required for the tethering of DNA ends, which promotes one of the two main pathways for the repair of DSBs, non-homologous end joining (NHEJ) ${ }^{20}$. MRX/MRN stimulates end-joining both in budding and fission yeast $\mathrm{t}^{22,23}$. The ATP binding and hydrolysis by Rad50 are also required to activate Tel1/ATM ${ }^{24,25}$. On the other hand, the 'open' state that results from ATP hydrolysis is competent for DNA binding by Mre11 and nucleolytic action, whereas Rad50 in the ATP-bound state blocks access to the nuclease-active sites ${ }^{26,27}$. The Sae2 factor is required for the endonuclease action of Mre $11^{28}$. Endonucleolytic cleavage also appears to require ATP hydrolysis and not just release from the 'closed' state, so it has been proposed that an intermediate state between 'closed' and 'open', yet to be observed, might exist to promote endonucleolytic action ${ }^{14}$. The endonuclease action of Mre11 is followed by an exonucleolytic one to resect DNA and help channel DSB repair away from NHEJ and toward homology-dependent repair (HDR) ${ }^{29,30}$.
Telomeres must deal with the multiple threats posed by MRN in potentially initiating NHEJ, HDR, or DDR signalling. Mammalian telomeres engage the telomere-binding protein TRF2 to suppress ATM signalling, presumably via formation of t-loop structures, and to directly bind Nbs1 to modulate repair outcomes at telomeres ${ }^{30,31}$. In budding yeast, a different mechanism for MRX control has been described, which relies on telomere protein Rif2. Rif2 is unique to budding yeast and closely related species (see below) and interacts with the C-terminal domain (RCT) of the main DNA-binding protein of budding yeast telomeres, Rap1, for its association with telomeres, where it suppresses telomere elongation and $\mathrm{NHEJ}^{32,33}$. The first clues that Rif2 is linked to the regulation of MRX-Tell came from epistasis analysis of telomere length and from a screen for suppressors of hydroxyurea sensitivity in Tel1-overexpressing cells, which produced Rif2 ${ }^{34,35}$. Rif2 inhibits MRX-dependent resection in $\mathrm{G1}^{36}$ and the tethering of DNA ends after DSB formation ${ }^{23}$. Interestingly, the binding of MRX to DSB is not severely diminished in the absence of Rif2, suggesting a regulatory role for Rif2 23,37 , an idea that is supported by the observation that Rif2 affects the ATPase activity of Rad50 23 .

We focus here on a conserved motif within Rif2, previously shown to be involved in the regulation of telomere length and Tell activation ${ }^{38,39}$, which we refer to as MIN for MRN-inhibitor. We show, by a combination of genetic and biochemical approaches, that the motif is a potent inactivator of MRX-Tel1, as it is capable of disabling the action of MRN-Tell in telomerase activation, NEHJ suppression and endonucleolytic digestion of DNA. Our data are consistent with a direct action of the motif on the $\mathrm{N}$ terminus of Rad50, and an effect on the ATP hydrolysis-dependent, Rad50-mediated allosteric transition enacted by Rad50 on the complex. We suggest that MIN provides a powerful and comprehensive mechanism for telomeres to inactivate the multiple actions of MRN-Tell at chromosome ends and that this mechanism has independently arisen in multiple lineages during fungal evolution.

\section{Results}

Identification of a conserved motif in Rif2 and Orc4. RIF2 evolved from the gene coding for the Origin Recognition Complex 4 subunit (ORC4) after a whole-genome duplication (WGD) event that occurred in budding yeast and related species (see below Fig. 1e for an illustration of evolutionary relationships of species discussed in this study) 33,40 . Therefore, to gain insight into the parts of Rif2 of possible functional significance (Fig. 1d), we decided to carry out an analysis of the Rif2 and Orc4 amino acid sequence aimed at identifying conserved and diverging regions. All yeast species bearing RIF2 also carry a copy of ORC4, the latter being an essential gene. Clustal Omega alignment of Rif2 and Orc4 protein sequences from several fungal species in the Saccharomycetceae clade revealed that Rif2, compared to its Orc4 counterpart, consistently bore an extra stretch of $\sim 30$ amino acid at the $\mathrm{N}$ terminus (Fig. 1a). Strikingly, a survey of Orc4 sequences in other Saccharomycotina species devoid of Rif2 revealed that several Orc4 proteins share homology at their $\mathrm{N}$ terminus to the N-terminal 'tail' region in Rif2 (Fig. 1b). A strongly conserved consensus motif can be derived from this analysis and is summarised in Fig. 1c. Four positions, in particular, appear to be invariantly conserved and correspond to positions 7 (D/E), 8 (F), 11 (ILMV) and 12 (KR) of S. cerevisiae Rif2, and we propose that these residues (in blue in Fig. 1c) delimit a core motif of functional significance (see below). In this manuscript, we will refer to this motif as the MIN motif, for MRX-inhibitory motif, based on its proposed function. 


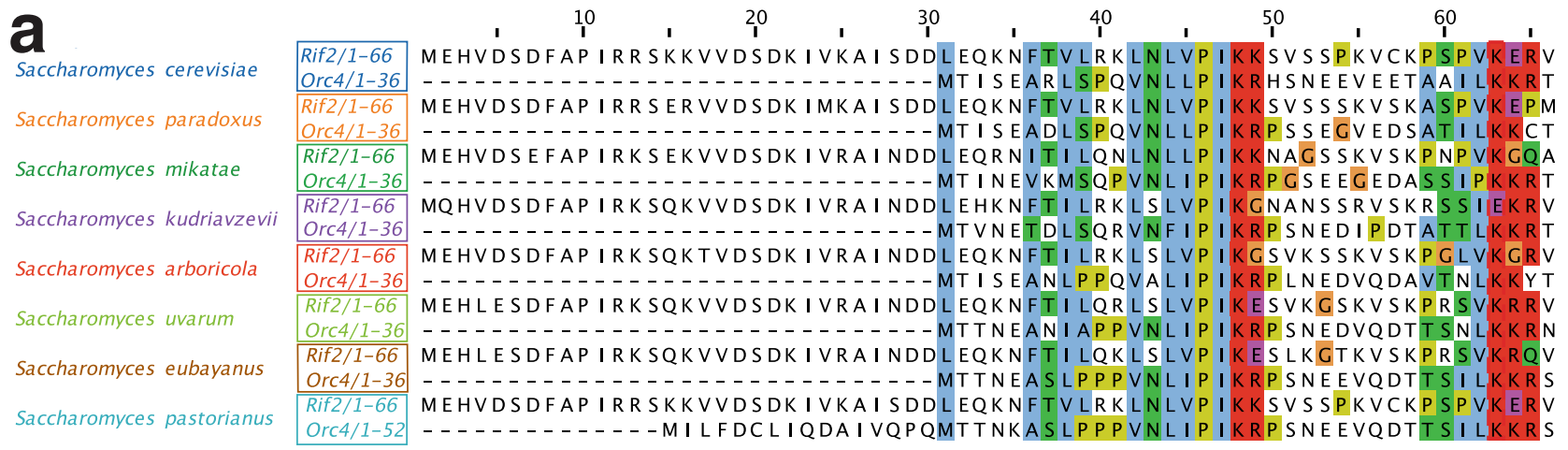

\section{b}

Saccharomyces cerevisiae Rif2/1-44 Saccharomyces paradoxus Rif2/1-44 Saccharomyces mikatae Rif2/1-44 Saccharomyces kudriavzevii Rif2/1-44 Saccharomyces arboricola Rif2/1-44 Saccharomyces uvarum Rif2/1-44 Saccharomyces eubayanus Rif2/1-44 Saccharomyces pastorianus Rif2/1-44 Candidata glabrata Rif2/1-41 Kazachstania naganishii Rif2/1-42 Kazachstania africana Rif2/1-44 Kazachstania saulgeensis Rif2/1-44 Naumovozyma castellii Rif2/14-59 Tetrapisispora phaffii Orc4/1-44 Vanderwaltozyma polyspora_Orc4/1-44 Tetrapisispora blattae Orc4/1-44 Torulaspora delbrueckii Orc4/1-44 Zygosaccharomyces bailii Orc4/1-44 Zygosaccharomyces rouxii Orc4/1-44 Zygosaccharomyces rouxii Orc4/1-44
Zygosaccharomyces mellis Orc4/1-44 Zygosaccharomyces parabailii Orc4/1-44 Lygosaccharomyces parabailii 14 Lachancea thermotolerans Orc4/26-70 Lachancea thermotolerans Orc4/26Lachancea nothofagi Orc4/34-77 Lachancea nothofagi Orc4/34-77 Lachancea meyersii Orc4/1-44 Lachancea fantastica Orc4/1-44 Lachancea lanzarotensis Orc4/1-44 Eremothecium gossypii Orc4/1-44 Ashbya aceri Orc4/1-44 Eremothecium sinecaudum Orc4/1-44 Eremothecium cymbalariae Orc4/1-44 Kluyveromyces marxianus Orc4/1-44 Kluyveromyces dobzhanskii Orc4/1-44 Kluyveromyces lactis Orc4/1-44 Hanseniaspora valbyensis Orc4/7-51 Cyberlindnera fabianii Orc4/7-52 Cyberlindnera jadinii Orc4/11-56 Candida intermedia Orc4/2-47 Clavispora lusitaniae Orc4/6-51 Candida auris Orc4/1-46 Candida haemulonis Orc4/1-46 Candida duobushaemulonis Orc4/1-46 Candida pseudohaemulonis Orc4/1-46 Candida dubliniensis Orc4/6-51 Candida dubiniensis Orc4/6-5. Metschnikowia pulcherrima Orc4/2-46 Spathaspora passalidarum Orc4/7-52 Debaryomyces fabryi Orc4/6-51 Debaryomyces hansenii Orc4/6-51 Debaryomyces hansenii Orc4/6-51 Komagataella pastoris Orc4/35-80 Komagataella phaffii Orc4/35-80
C

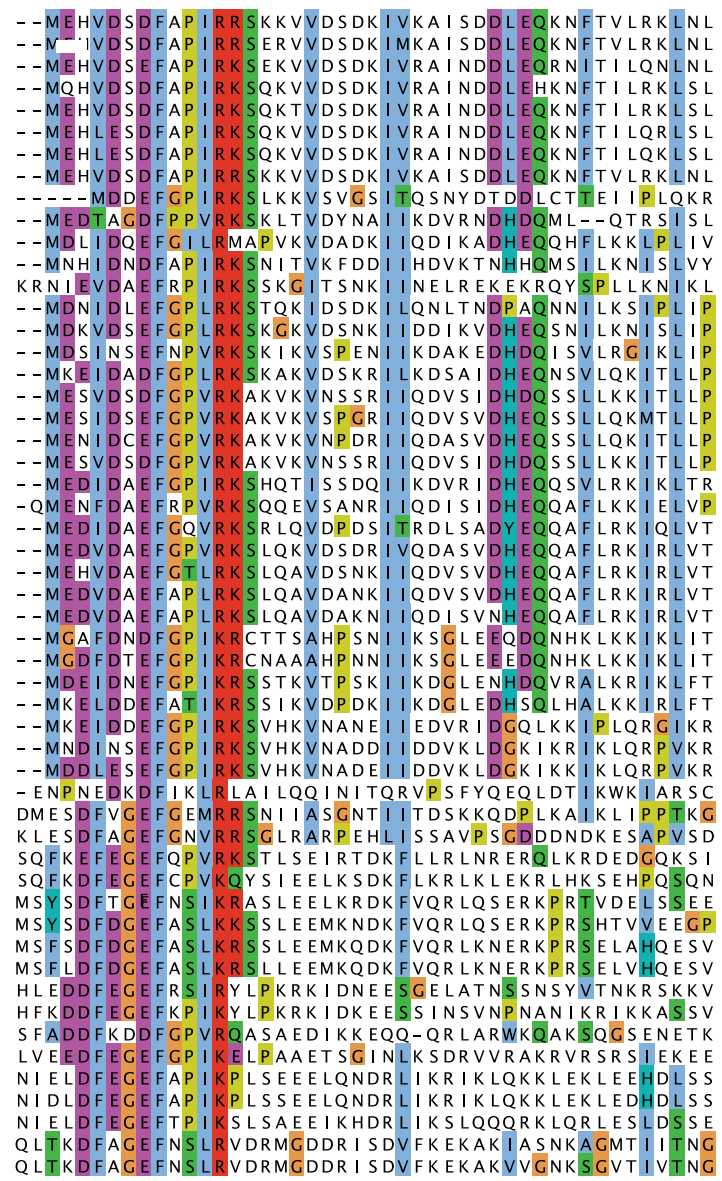

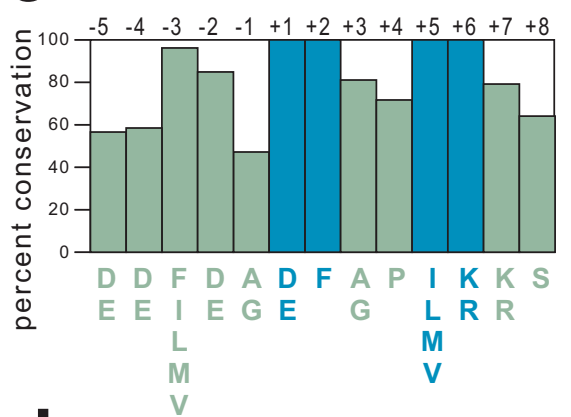

0

Saccharomyces cerevisiae Rif2

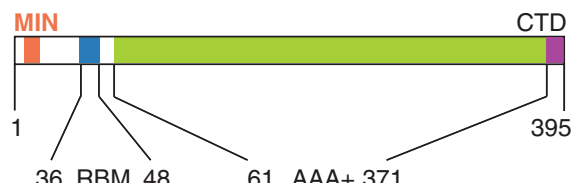

36 RBM 48

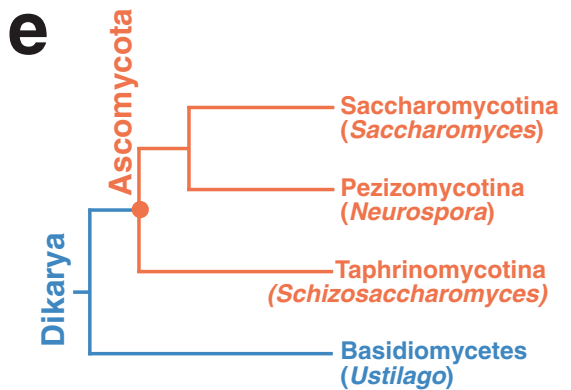

Fig. 1 A conserved protein motif at the $\mathbf{N}$ terminus of Rif2 and Orc4 in the Saccharomycotina. a Sequence alignments of the indicated Rif2 and Orc4 proteins from Saccharomycotina species where Rif2 is present were produced in Clustal Omega and gaps were manually eliminated. Amino acid included are indicated after the protein name. Alignments were done using the Clustal Omega interface on the EBI site. Alignments were edited (in this case) and imaged in Jailview using Clustalx colouring of conserved residues (panels $\mathbf{a}, \mathbf{b}$ and Fig. 7a). b Sequence analysis as in (a) of Rif2 and Orc4 N-terminal regions from species where the conserved region identified in the $\mathrm{N}$-terminal extension in (a) is present. Species are broadly arranged top to bottom according to the phylogeny described in ref. ${ }^{74}$. c Diagram illustrating the prevalence of conserved residues in the $\mathrm{N}$-terminal cluster derived from the alignment in (b), defining the MIN motif. Based on the presence of four invariant residues (see also Fig. 7b) we adopt for the motif the numbering indicated on top of the diagram (invariant positions at $+1,+2,+5$ and +6 , in blue). $\mathbf{d}$ Diagram of the domain structure of budding yeast Rif2. Conserved domains previously identified in ScRif2 include an AAA+ fold shared with Orc4, and a Rap1-binding motif (RBM) at the N terminus and one (CTD, C-terminal domain) at the $\mathrm{C}$ terminus ${ }^{61}$; the position of the MIN motif is shown in orange. e Phylogenetic tree, showing the relationship among the three clades comprising the Ascomycota. Representative species are indicated within parenthesis. Adapted from ref. ${ }^{75}$.

The MIN motif regulates telomere length through the MRXTell pathway. Previous scanning mutagenesis analysis of RIF2 revealed that a small $\mathrm{N}$-terminal region in Rif2 is responsible for regulating telomere length in budding yeast and defined the first 60 amino acids of ScRif2 as the BAT domain, for 'Blocks Addition of Telomeres' ${ }^{38}$. The BAT domain fully contains the MIN motif and the mutagenesis investigation of BAT is broadly consistent with the analysis of sequence conservation (Fig. 1b), in that some of the most strongly conserved positions within the Sc MIN (particularly F8) were found to have the strongest telomere length 
phenotype when changed to alanine ${ }^{38}$. Intriguingly, BAT lays within a small $\mathrm{N}$-terminal fragment previously proposed to interact with the $\mathrm{C}$ terminus of $\mathrm{Xrs} 2$ and to compete for its binding to Tel1 ${ }^{37}$. This raised the possibility that MIN might function by promoting the binding of Rif2 to Xrs2 and thus disabling its critical function in the Tell activation of telomerase. Although earlier experiments concluded that BAT does not act by affecting the function of the Xrs2 $\mathrm{C}$ terminus in telomere length regulation ${ }^{38}$, this analysis was carried out with an $x r s 2$ allele only partly defective for Tell binding, and showing only a mild telomere shortening phenotype ${ }^{41}$. In fact, Xrs2 carries two putative Tel1-interacting motifs at its $\mathrm{C}$ terminus and impairment of both motifs is required to confer significant telomere shortening ${ }^{16,38,42}$. In order to determine whether the Rif2 MIN motif acts through the MRX-Tel1 pathway of telomerase regulation, we carried out epistasis analysis of telomere length using xrs2- and tel1-null alleles, as well as C-terminal truncation of Xrs2, which ablates both Tel1-interacting motifs in the protein and fully disables Tel1 recruitment to telomeres ${ }^{42,43}$. This allele, $x r s 2-664$, confers telomeres as short as the $x r s 2$ - or tel1-null alleles and is, therefore, an ideal choice for epistasis analysis (Fig. 2a). As expected, a rif2 allele carrying two-point mutations within the MIN motif (F8E and P10N mutations, rif2-min allele) generated telomeres at least as long as the rif2 null. An examination of telomere length in the double mutants carrying the null allele pairings rif2- $\Delta$ xrs2- $\Delta$ and rif2- $\Delta$ tell- $\Delta$ showed, as anticipated based on the previously recognised role of Rif 2 in modulating MRX-Tel1 function ${ }^{35,44}$, a dramatic shortening of telomere length near the levels seen in the $\operatorname{xrs} 2-\Delta$ and tell- $\Delta$ single mutant strains. Importantly, we observed similarly shortened telomeres in double mutant configurations where the rif2- $\Delta$ allele was replaced by the rif2-min allele, suggesting that the Xrs2 $\mathrm{C}$ terminus and the Tel1 kinase are both required for the telomere elongation effect conferred by loss of the MIN motif in Rif2. Thus, as mutations in the MIN motif are epistatic to $x r s 2 / t e l 1$, the simplest interpretation of these results is that MIN acts by impairing the pathway of telomerase activation that relies on the MRX-dependent recruitment of the Tel1 kinase.

If the MIN motif impairs the action of the MRX-Tel1 complex, it is possible that ectopic overexpression of only the N-terminal Rif2 region containing MIN, incapable to locate telomeres due to the lack of binding to Rap1, might render cells hypersensitive to genotoxic stress, reminiscent of MRX mutants. In order to test this idea, we over-expressed peptides bearing the first 34 amino acid residues of Rif2 from the strong galactose-inducible promoter. In line with the hypothesis above, we found that
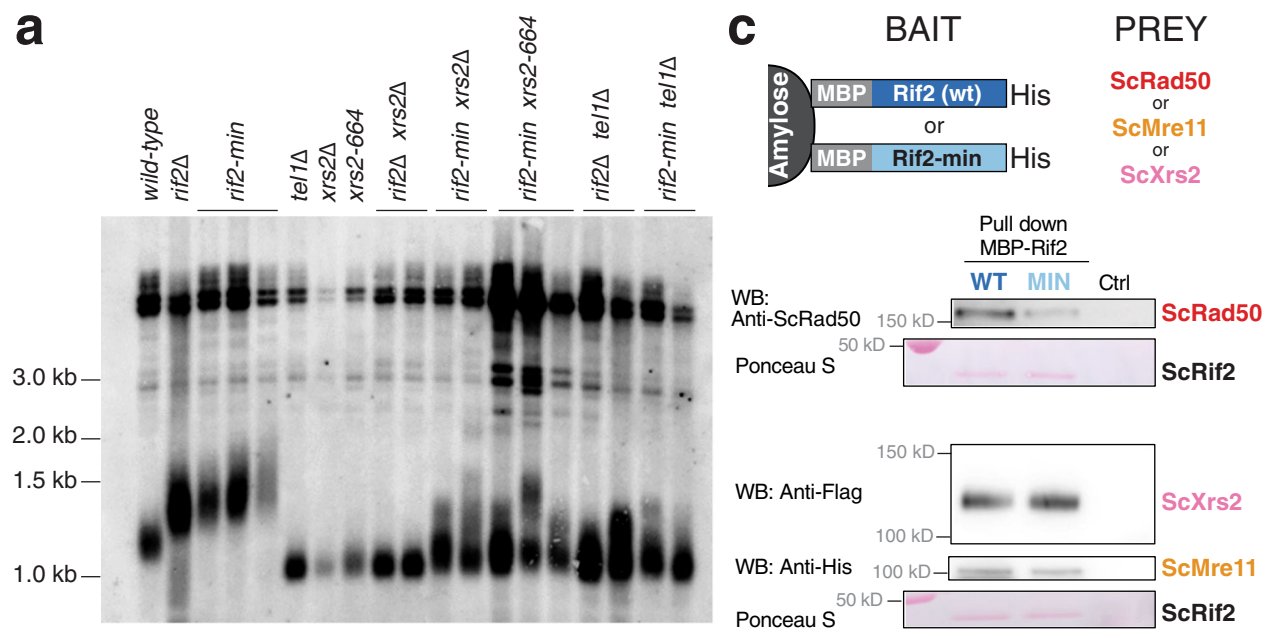

b

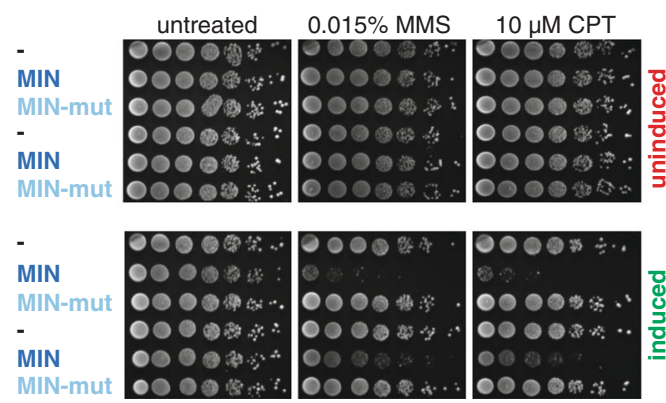

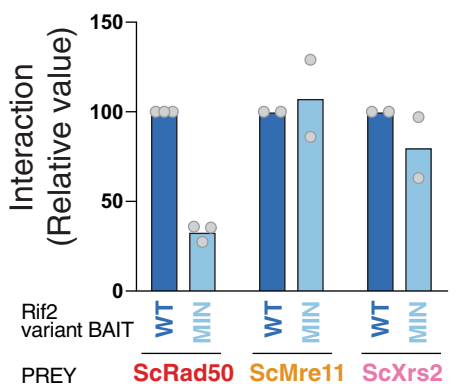

Fig. 2 The MIN motif of Rif2 counteracts the action of the MRX complex in promoting telomere elongation and promotes binding to Rad50. a Southern blot analysis of telomere length of Saccharomyces cerevisiae strains of the indicated genotypes. Genomic DNA was digested with Xhol and detected using a telomeric probe. ' $\Delta$ ' indicates null alleles obtained by full deletion of the coding sequence. The rif2-min allele carries an F8E P1ON substitution. $\mathbf{b}$ Viability assays of strains overexpressing a fusion protein containing the first 34 amino acids of Rif2 under control of the galactose-inducible promoter, either in wild-type form (MIN) or mutant (MINmut, carrying the double F8E P10N substitution). Strains were grown in glucose-containing rich medium (YPAD) before plating onto either glucose (uninduced, top row) or induced (galactose, bottom row) plates containing the indicated chemicals and incubated at $30{ }^{\circ} \mathrm{C}$ for 2-3 days. c Protein interaction assays with immobilised wild-type or mutant Rif2 (Rif2-min) as bait, and Rad50, Mre11 or Xrs2 proteins used individually as prey. The bound proteins were separated by electrophoresis and detected by Western blotting (for Rad50, anti-Rad50; for Mre11-his, antihis; and for Xrs2-FLAG, anti-FLAG), or by Ponceau S staining (for Rif2 wild-type or Rif2-min). CTRL lane is prey protein incubated with amylose resin without bait. A representative blot is shown, as well as a quantification of 2-3 independent ones, as indicated. Source data are provided as a Source Data file. 
overexpression of the MIN motif, but not a mutant version bearing the $\mathrm{F} 8 \mathrm{E}$ and $\mathrm{P} 10 \mathrm{~N}$ mutations, rendered the cells hypersensitive to treatment with methyl methanesulfonate (MMS) or camptothecin (CPT) (Fig. 2b). Thus, expression of this large truncation allele of Rif2, containing only the MIN motif, has a dominant-negative effect on the ability of cells to enforce DDR, consistent with a possible inactivating role on MRX.

Tell is pivotal in the telomerase-dependent pathway of telomere maintenance in budding yeast, but less crucial in assisting the DNA repair function of the MRX complex in budding yeast ${ }^{23,45}$. In particular, Tel1 is required to guarantee resistance to genotoxic stress by $\mathrm{CPT}$, but not $\mathrm{MMS}^{46}$. If the MIN motif acted solely by affecting Tell recruitment to the complex, via the Xrs2 $\mathrm{C}$ terminus, its overexpression might have been expected to have displayed specificity towards CPT sensitivity, instead of affecting sensitivity to MMS as well, as we observed (Fig. 2b). We, therefore, decided to address whether Rif2 might function by targeting other subunits of the MRX complex instead of the Xrs2 C terminus. In pull-down assays with purified components, Rif 2 was found to be able to interact with all three subunits of the complex (Fig. 2c). Interestingly, the F8E P10N mutations reduced, although they did not abolish, the ability of Rif2 to interact with Rad50, but not with Mre11 and Xrs2, suggesting that the interaction with Rad50 might be the more relevant one with regard to the action of the MIN motif. Taken together, these results indicate that the MIN motif in Rif2 acts at telomeres by directly affecting the action of the MRX complex. In agreement with a recent biochemical study ${ }^{39}$, this effect of MIN is likely exerted through an interaction on the Rad50 subunit. While that study has reported that an F8A mutation in Rif2, which impairs the ability of Rif2 to modulate MRX, does not affect the interaction with Rad50, the double mutant studied here shows diminished binding, suggesting that multiple contributions are made by MIN motif residues in contacting $\operatorname{Rad} 50^{39}$.

The MIN motif is required for the suppression of checkpoint activation at telomeres by Rif 2 . Rif2 has a protective function at telomeres by both preventing exonucleolytic degradation and activation of the $\mathrm{DDR}^{47,48}$. Because the MRX-Tel1 complex contributes to the DDR response at unprotected telomeres, we tested the hypothesis that Rif2 might carry out its role in suppressing DDR activation at telomeres through the action of the MIN motif. To do so, we employed an assay first described by the Weinert lab that relies on the induction of a DSB by the HO endonuclease at a chromosomal site flanked by telomeric repeats ${ }^{49}$. In our setting, the DSB is flanked at both ends by telomeric repeats ${ }^{48}$. The DNA break was induced, and smallbudded cells, indicative of the early S-phase stage, were micromanipulated on a plate, and then inspected over several hours to measure the kinetics of progression through the cell cycle. Specifically, the length of the arrest in the G2/M phase following the break, as indicated by dumbbell-shaped cells, was monitored: while wild-type cells are expected to cycle quickly, as the DDR is not activated due to the protective effect of the telomeric repeats flanking the newly generated DNA ends, mutations affecting telomere protection will disable the checkpoint-suppressive function and result in transient cell cycle arrest in G2/M. In this assay, checkpoint activation is affected by Mre11, and increases in resection and in Mre11 and Tell association are observed at the break ${ }^{48}$. At least two independent pathways contribute to checkpoint suppression in this setting, one dependent on Rif1 and one dependent on Rif ${ }^{48}$. We set out to test whether the contribution of Rif2 to checkpoint suppression relies on the MIN motif. As previously described, loss of Rif1 and Rif2 caused additive delays in the release from $\mathrm{G} 2 / \mathrm{M}$ in this assay
(Fig. 3a). Remarkably, in both the presence or absence of Rif1, the rif2-min allele produced the same effect as the rif2-null allele (Fig. 3a), indicating that the MIN motif is required for the ability of Rif2 to prevent checkpoint activation at unprotected telomeric DNA ends.

The MIN motif of Rif 2 suppresses NHEJ. In budding yeast, the MRX complex is required to promote DSB repair by NHEJ, and Rif2 suppresses NHEJ at telomeres ${ }^{33}$. Because we showed that the Rif2 MIN motif limits the ability of MRX to promote telomere length, we addressed whether the motif might also be responsible for the disabling effect of Rif2 on NHEJ. DSB repair events can be channelled into the NHEJ pathway in the absence of an intact homologous sequence that could serve as a template for repair by homologous recombination. NHEJ can be measured by assessing the ability of haploid budding yeast cells to survive a double DSB flanking a selectable marker ${ }^{3}$. In this setting, telomeric sequences positioned near one of the two breaks cause decreased survival upon DSB induction, due to their suppression of NHEJ, at least partly via the Rap1-promoted recruitment of Rif $2^{33}$. The effect of telomeric repeats in this assay can be bypassed by directly tethering the RCT near the DSB by fusing it to the Gal4 DNAbinding domain (GBD) and placing copies of its recognition site (UASg) near the break. As expected, the presence of UASg sites near the break led to decreased survival upon the presence of a GBD-RCT fusion protein (Fig. 3b). Deletion of Rif2 rescued the viability defect, due to loss of NHEJ inhibition and consequent DSB healing. Crucially, the effect of the UASg/GBD-RCT combination depended on the presence of a functional MIN motif in Rif2, as the phenotypes of rif2- $\Delta$ and rif2-min strains were indistinguishable in this assay, indicating that the motif is required for the suppression of NHEJ by Rif2.

The observation that the role of the BAT domain in telomere length suppression did not require the RCT domain of Rap $1^{38}$ predicts that tethering MIN directly to the break site, via the expression of a GBD-MIN fusion, should mimic the effect seen with the tethered RCT domain. Indeed, a decrease in survival was obtained when the first 40 amino acids of Rif2 were fused to GBD, while the F8E P10N double mutation abolished the NHEJsuppressive effect of this small Rif2 N-terminal fragment fusion (Fig. 3b). Taken together, these results indicate that the MIN motif of Rif2 is both necessary and sufficient to achieve the suppression of NHEJ in DSB repair by Rif2.

Interestingly, Tel1 was not required for the RCT to suppress NHEJ, suggesting that the effect of MIN in this setting occurs via the MRX complex itself, rather than via targeting the action of the Tell kinase, unlike in the case of the regulation of telomere length. This result is consistent with the suggestion, as described above, that the MIN motif acts via an interaction with $\operatorname{Rad} 50$, rather than by affecting the ability of Xrs2 to recruit Tel1, as originally proposed for Rif $2^{37}$. Because the rif2-min allele mimics the rif2 null with regard to both telomere length and telomere protection, we think it is unlikely that the MIN motif, and by extension Rif2, acts via the Xrs2-Tel1 recruitment axis, even in telomere length regulation. Rather, these results are consistent with a model recently proposed whereby the Rif2 N-terminal region affects the ability of the MRX complex to activate the Tell kinase and specifically the ability of the Rad50 subunit to trigger its activation 25,39 . Our results indicate that MIN affects a broad spectrum of MRX activities besides Tel1 activation, including specifically NHEJ.

The MIN motif disables the endonucleolytic function of MRX. Our in vivo data indicate that the functions of Rif2 in telomere length regulation, suppression of the DNA damage checkpoint at 


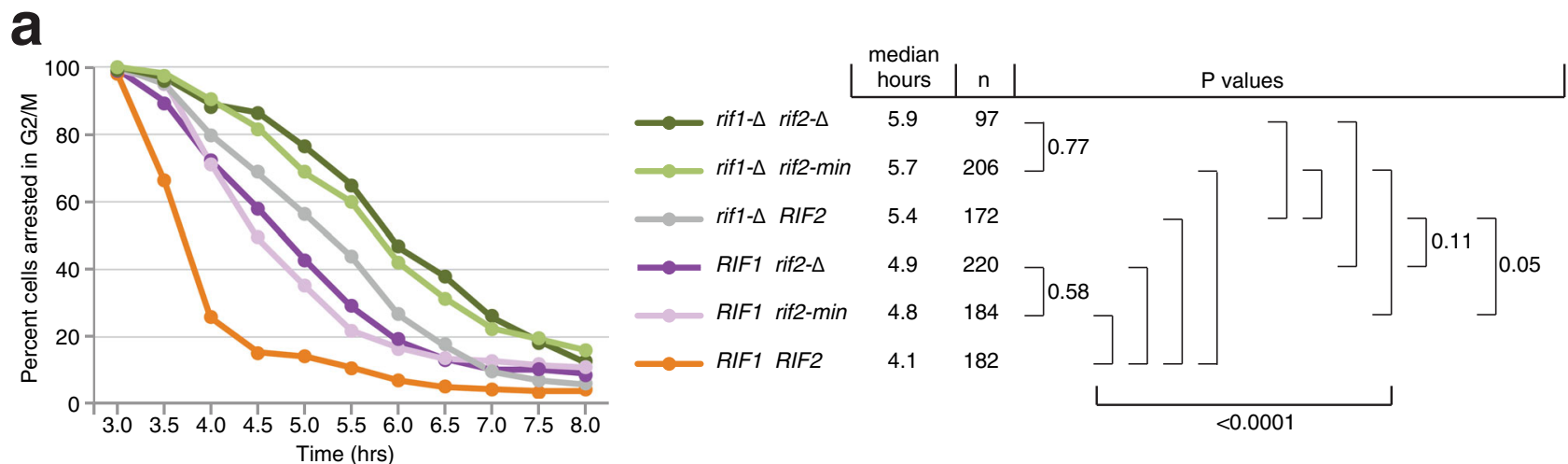

b

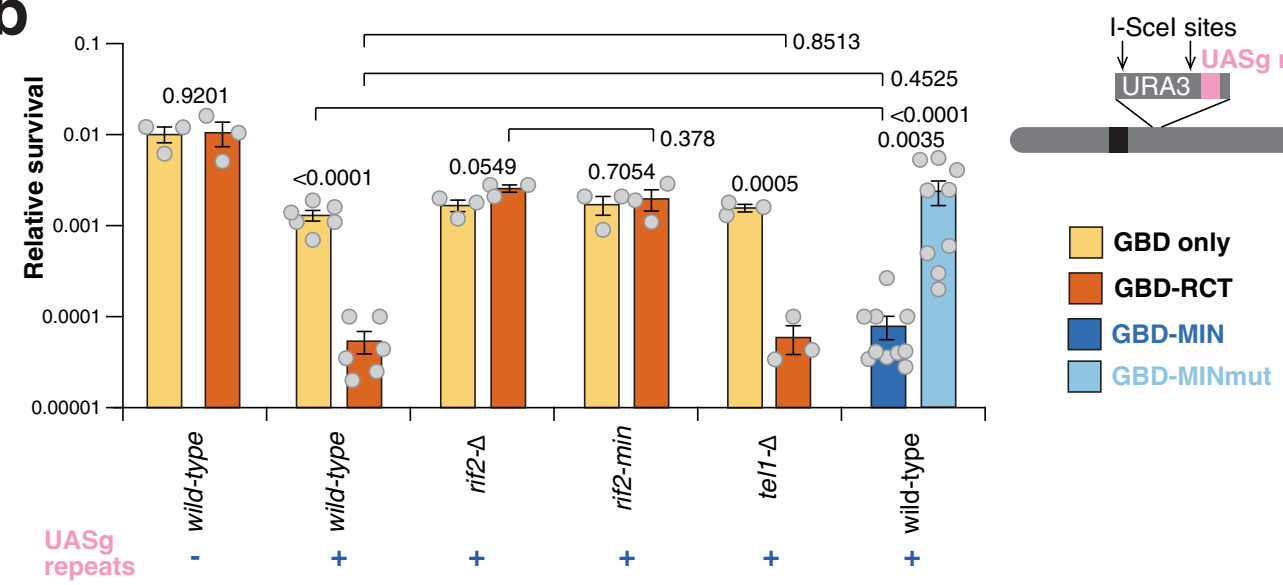

Fig. 3 The MIN motif enforces the suppression of the DDR and NHEJ at a DSB flanked by telomeric repeats. a A specific DSB, flanked by telomeric repeat arrays at both ends, was induced at the ADH4 locus on the left arm of chromosome VII by expression of the $\mathrm{HO}$ endonuclease in galactosecontaining medium. After induction of the break, cells in the $\mathrm{S}$ phase were monitored for their ability to escape G2/M arrest. The percentage of G2/Marrested cells, from at least three independent experiments for each genotype (two for rif1- $\Delta$ ), was estimated using the Kaplan-Meier analysis by GraphPad Prism (log-rank test). b Viability assays to quantify the ability of cells to survive a double-inducible DSB on either side of the URA3 gene on chromosome V. Strains were grown in minimal medium lacking uracil and tryptophan, and then plated out on plates containing glucose (to assess plating efficiency) or galactose (to assess survival after cleavage). GBD is Gal4 DNA-binding domain, RCT is the Rap1 C-terminal domain, MIN contains Rif2 amino acids 1-40, and the MINmut version carries the F8E P10N mutations. Relative survival was determined from at least three independent experiments; the number of independent cultures analysed was 3, 3, 6, 6, 3, 3, 3, 3, 3, 3, 10, 9 for strains from left to right. Data are presented as mean with SEM. $P$ values are reported for each pair of datasets as indicated and were obtained with a two-tailed, unpaired $t$ test. Source data are provided as a Source Data file.

telomeres, and inhibition of NHEJ at telomeres are mediated by the MIN motif. In addition, epistasis analysis implicated the MIN motif of Rif2 in the control of MRX-Tel1, and mutating the motif diminished its ability to physically interact with Rad50, firmly linking the MIN motif with MRX functionality. To get insights into the mechanism of action of the MIN motif on the MRX complex, we expressed and purified recombinant full-length Rif2, in wild-type and the F8E P10N mutant form (Fig. 4a), and tested its effect on various activities of the purified MRX complex. As observed previously ${ }^{23}$, Rif 2 was found to stimulate the ATPase activity of the MRX and MR complexes (Fig. 4b). Importantly, the F8E P10N mutations ablated this stimulatory effect (Fig. 4b). The ATPase activity of the Rad50 subunit is instrumental in promoting conformational changes in the complex, which modulate its activity in DNA end resection and tethering as well as Tel1 kinase activation ${ }^{20}$. This raised the possibility that the MIN motif of Rif2 might directly impair the nucleolytic function of the MRX complex. To test this, we assayed nuclease activities of the MRX complex in the presence of wild-type and mutant Rif2. Previously, it has been established that MRX has a $3^{\prime}-5^{\prime}$ exonuclease activity that does not require ATP hydrolysis (Fig. 4c, left), and Mre11 alone is necessary and sufficient for this function ${ }^{50,51}$. In addition, MRX employs its endonucleolytic activity to resect DSBs with protein blocks. The endonucleolytic cleavage by the nuclease of Mre11 requires ATP hydrolysis by Rad50, as well as phosphorylated Sae2 (pSae2) as a co-factor (Fig. 4c, right ${ }^{28,52}$. We employed a substrate used previously, which allows monitoring both exonuclease and endonuclease activities simultaneously (Fig. 4c $)^{52}$. We observed that Rif2, whether in its wild-type or mutant form, had no effect on the exonuclease action of MRX, while wild-type Rif2, but not the Rif2-min mutant, was found to strongly reduce the endonuclease action of MRX in the presence of Sae2 (Fig. 4d-i). This inability of the mutant to suppress endonucleolytic cleavage was not due to decreased DNA-binding activity, as both mutant and wild-type variants of Rif2 retained DNA-binding capability (Fig. 4j).

Rad50 is a key regulatory component in the MRX complex, which triggers ATP-dependent conformational switches to regulate its various functions. ATP binding by $\operatorname{Rad} 50$ is required for Tel1 activation by MRX and end tethering in $\mathrm{NHEJ}^{19,20,53}$, and ATP hydrolysis is required for the Rad50-dependent endonucleolytic action of Mre1128,50. Accordingly, Rad50 mutants lacking ATP-binding activity recapitulate the multiple phenotypes of the null allele ${ }^{54}$. The ability of Rif2 to interact with Rad50, which is at least partly dependent on the MIN motif, and the requirement of the MIN motif to stimulate the Rad50 ATPase 

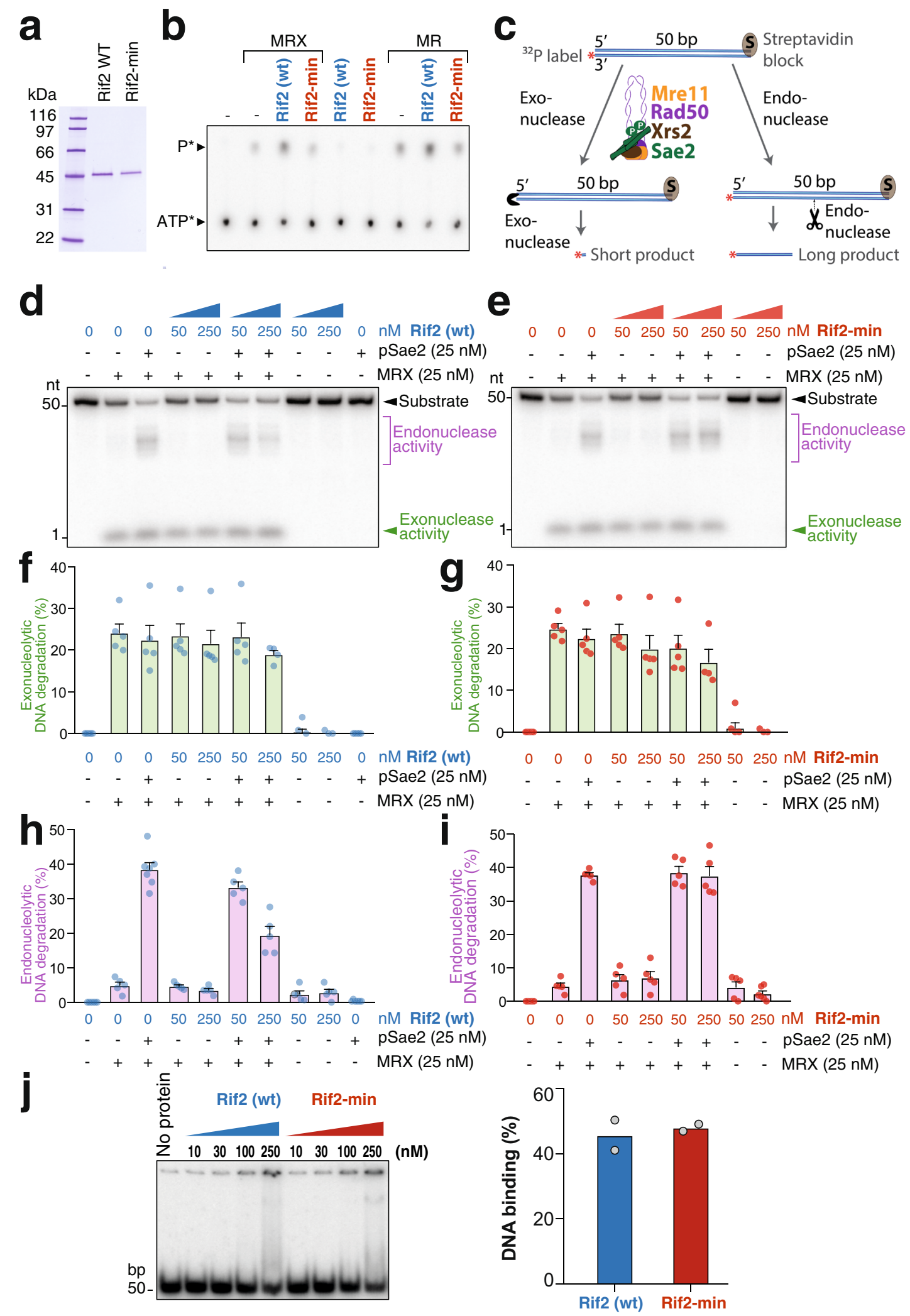

activity, suggest that Rif2 inactivates the multiple functions of MRX by triggering non-productive ATP hydrolysis by the MRX complex, and hence enforcing ATP-dependent conformational changes of the complex. It was recently shown that the F8 residue on Rif2 is instrumental in impairing the ability of Rad50 to activate Tel1, explaining the telomere length phenotype of the MIN motif mutants, which we here show is epistatic to the Xrs2-
Tel1 pathway (Fig. 2) ${ }^{39}$. The suppression of NHEJ that we now report is also consistent with a MIN-dependent switch of the complex to an 'open' conformation after ATP hydrolysis. The nuclease data presented here further support this model, as we show that only the ATPase-dependent endonuclease activity of MR (or MRX) is affected, but not the ATPase-independent exonuclease activity. In this scenario, MIN is proposed to 
Fig. 4 The MIN motif of Rif2 is required to suppress the endonucleolytic activity of MRX. a Purified S. cerevisiae wild-type Rif2 and MIN-mutated Rif2min variants used in this study. The polyacrylamide gel was stained with Coomassie Blue. b Representative ATPase assay with MRX (100 nM), MR (100 $\mathrm{nM}$ ), wild-type Rif2 (500 nM), or Rif2-min (500 nM), as indicated. c A scheme of the nuclease assay used to monitor the exonuclease and endonuclease activities of the MRX complex in the presence of phosphorylated Sae2. The radioactive label is at the 3' position on the bottom DNA strand. The 3'-5' exonuclease activity gives rise to a small product that migrates at the bottom of the gel. The endonuclease activity yields longer products. $\mathbf{d}$ Nuclease assays with MRX, phosphorylated Sae2 (pSae2) and wild-type Rif2, as indicated. Shown is a representative experiment. e Nuclease assays as in (d), but with Rif2-min (F8E P10N mutations). f, $\mathbf{g}$ Quantitation of exonucleolytic data such as shown directly above in (d, e), respectively. Error bars represent SEM for five independent experiments. $\mathbf{h}, \mathbf{i}$ Quantitation of endonucleolytic data as shown directly above in (d, e), respectively. Error bars represent SEM for five independent experiments. $\mathbf{j}$, Left panel: representative electrophoretic mobility shift assays with Rif2 (wt) and Rif2-min with the indicated protein amounts. Right panel: quantitation of data such as in the gel shown at left, with $250 \mathrm{nM}$ Rif2 (wt) or $250 \mathrm{nM}$ Rif2-min; $n=2$, averages and individual data points are shown. Source data are provided as a Source Data file.

promote ATP hydrolysis by MRX (or MR) in a non-productive manner and thus prevent productive hydrolysis that would lead to endonucleolytic action. This conclusion agrees with previous data suggesting that Rif2 discharges the ATP-bound form of Rad50 to attenuate Tel1 activity ${ }^{39}$. In summary, these results support a scenario where the MIN motif of Rif2 converts the MRX-ATP complex to the open form, which broadly impairs the MRX complex in its function to promote DNA repair, DDR signalling and telomerase regulation.

The MIN motif of Rif 2 interacts with the N-terminal region of Rad50. Among the characterized alleles of the MRX subunits, the rad50S allele stands out in that it leads to telomere elongation, rather than shortening as is seen in rad50-null cells ${ }^{10}$. The rad50S alleles (generally represented by the rad50-K81I mutation) comprise a small group of mutations originally identified for their meiotic phenotype in being defective in the resection of meiotic DSBs and removal of Spol1 from the breaks ${ }^{28,55}$. The phenotype of rad50S mutants is similar in many respects to that of strains defective in the nuclease activity of Mre11 or lacking Sae2, which is required to stimulate the endonucleolytic action of Mre11 (reviewed in ref. ${ }^{56}$ ). Rad50S cells, however, differ in one significant aspect, telomere elongation, as mre11 strains defective in endonucleolytic activity have normal telomere length, as do sae2null mutants ${ }^{57,58}$. The failure to promote nucleolytic processing of DNA ends, therefore, cannot explain the elongated telomeres promoted by Rad50S.

The rad50S mutations are clustered in a small region at the $\mathrm{N}$ terminus of the Rad50 protein, near the Walker A-type ATPase motif, in the part of the protein that contributes to half of the globular 'head' domain, and have recently been shown to define an area that is likely to provide the binding interface for phosphorylated Sae2, as the latter was shown to be incapable of binding the Rad50-K81I protein ${ }^{52}$. Prompted by the observation that the Rif2 MIN motif binds Rad50, we reasoned that the rad50S telomere phenotype could be explained if rad50S alleles failed to bind a repressor of MRX activity. We thus set out to test the idea that Rad50-K81I (from here onwards referred to as 'Rad50S') might be defective in MIN binding. To begin with, if the K81I mutation abolished the interaction with Rif2, then rad50S and rif2-min (or rif2- $\Delta$ ) alleles would be predicted to be epistatic with regard to their effect on telomere length. As expected, single mutants showed telomere elongation, with rif2 mutations conferring longer telomeres than rad50S, and rif2-min strains bearing slightly longer telomeres than rif2-null ones (Fig. 5a). Importantly, both rad50S rif2- $\Delta$ and rad50S rif2-min double mutant strains had telomeres of very similar length to rif 2 single mutants, indicating that these rad50 and rif2 alleles are largely epistatic, and consistent with the idea that an interaction between the two proteins is compromised in both mutants.
To test this idea directly, we performed yeast two-hybrid assays between wild-type and mutant variants of Rad50 and Rif2. Since we were interested to test interactions in the globular region of Rad50, we constructed a variant of the gene lacking the large central portion that codes for the CCs. As anticipated, we found that this variant, which we call Rad50head, is capable of interacting with Mre11 and, confirming the pull-down results with purified proteins (Fig. 2c), also with full-length wild-type Rif2 (Fig. 5b). Instead, the presence of either the min mutation in Rif2 (full-length and truncated) or the $S$ mutation in Rad50 abolished the interaction in this assay. In agreement with this result, we also found that mutant Rad50S was impaired in its interaction with Rif2 in the pull-down assay with purified proteins (Fig. 5c). We note that the yeast two-hybrid assay appears to be more stringent as the interaction was not completely abolished in the pull-downs, no matter whether Rif2 or Rad50 was mutated (Figs. $2 c$ and $5 c$ ), leaving open the possibility that other regions of Rad50 might interact with Rif2 (multiple interactions for both Rif2 and Sae2 are observed with various components of MRX; Fig. $2 c^{52}$ ). However, we did not detect additive effects when testing the two mutant variants in this assay (Fig. 5c), suggesting that the specific interaction at this interface might be equally, and in terms of physiological relevance possibly completely, disrupted in the two mutants.

The interaction data support the epistasis analysis of telomere length in the mutants. To further evaluate the functionality of this interaction in vivo, we decided to test the possible suppressive effect of the rad50S allele on two of the MIN phenotypes that we described earlier. The interpretation of the increased sensitivity of cells overexpressing MIN to genotoxic agents (Fig. 2b) is that MIN directly interacts with MRX to disable its function in repair. So, if MIN requires the K81 residue to interact with Rad50, then the rad50S allele would be predicted to suppress the decreased viability for strains overexpressing MIN upon exposure to CPT and MMS. Indeed, in a rad50S background, we observed a rescue of the MIN-dependent toxicity to both these drugs (Fig. 5d). Similarly, we found that the ability of MIN to impair healing of a DSB by NHEJ when tethered near the break (Fig. 3b) was partly compromised in strains bearing the rad50S allele (Fig. 5e); in other words, rad50S suppressed the ability of MIN to inhibit NHEJ when tethered near the DSB. Interestingly, and in agreement with the MMS and CPT sensitivity data reported in Fig. 2b, MIN was still able to inhibit healing of the break even in the absence of tethering, suggesting that overexpression of a functional MIN has an overall dampening effect on NHEJ within the cell. Taken together, these results identify the region in Rad50 that is responsible for a functional interaction with Rif2 via the MIN motif. Further studies will be required to elucidate the interplay between Rif2, Sae2, and Rad50 interactions, but these data provide a molecular rationale for the longstanding observation of elongated telomeres 


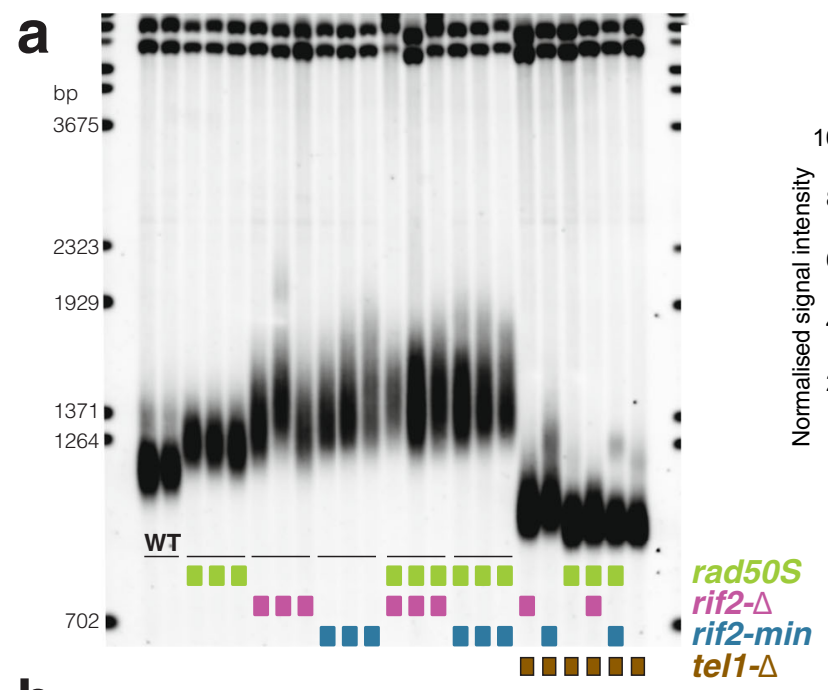

b

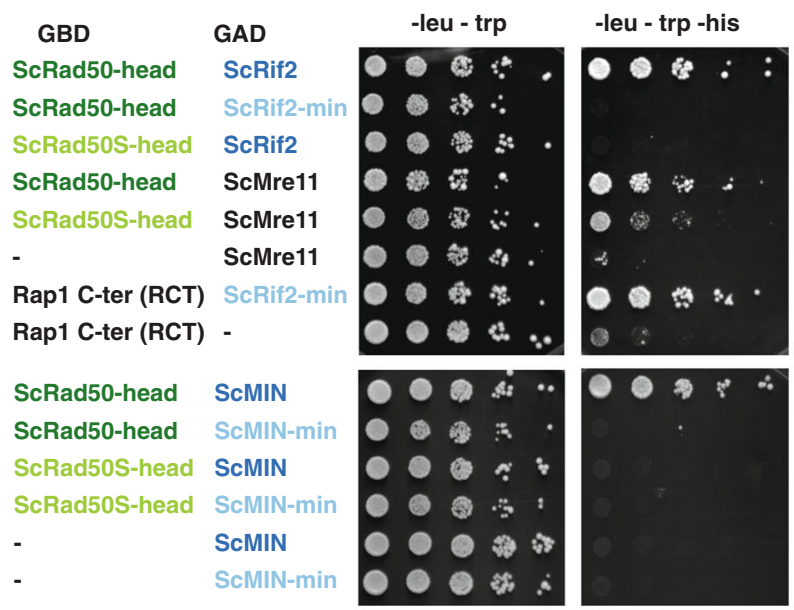

d

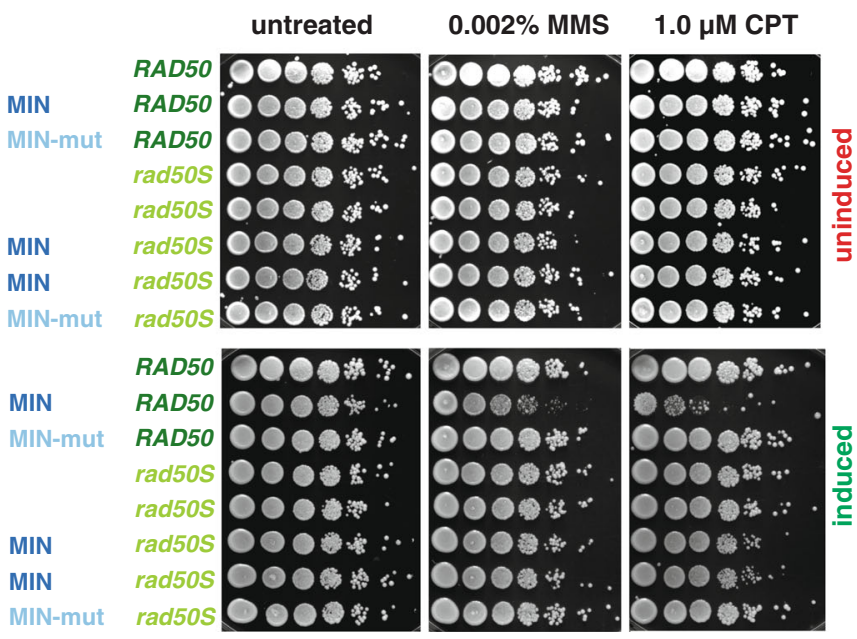

$$
\begin{aligned}
& \text { - wild-type } \rightarrow \text { rif2-min } \\
& \rightarrow \operatorname{rad50S} \rightarrow \operatorname{rad50S} \text { rif2- } \Delta \\
& \text { - rif2- } \triangle \quad \text { rad50S rif2-min }
\end{aligned}
$$
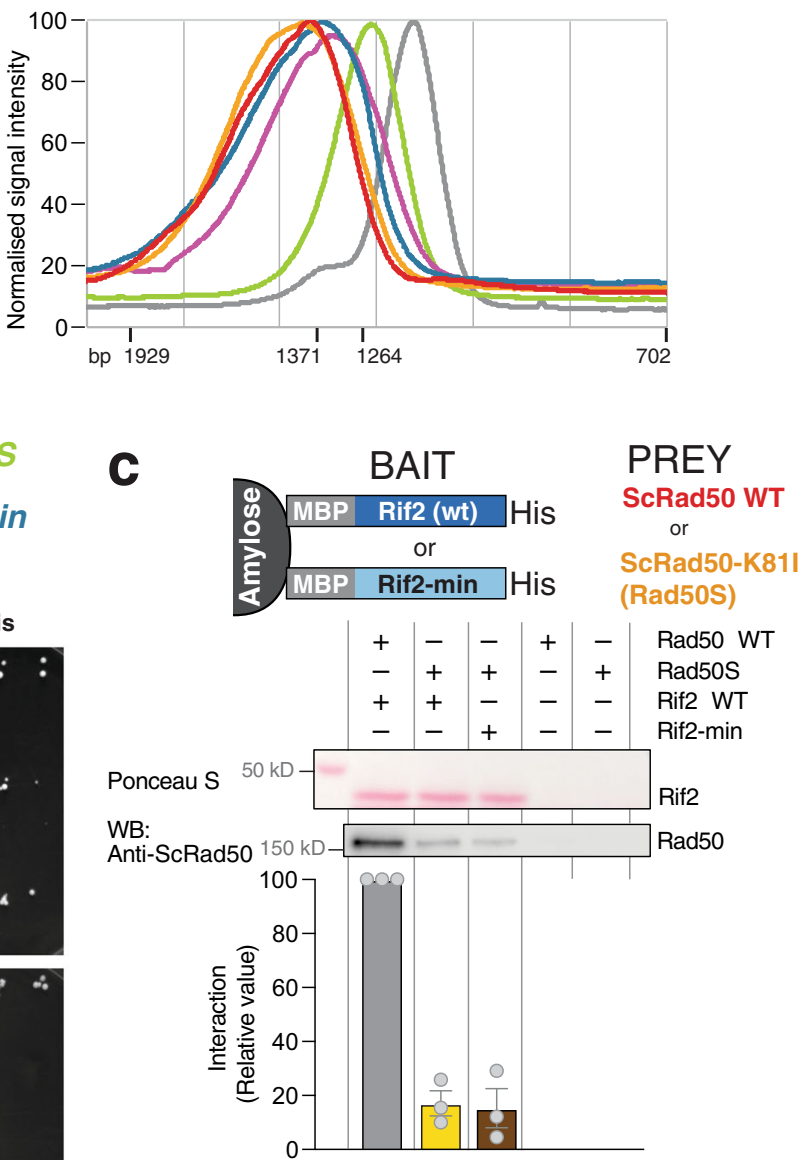

e

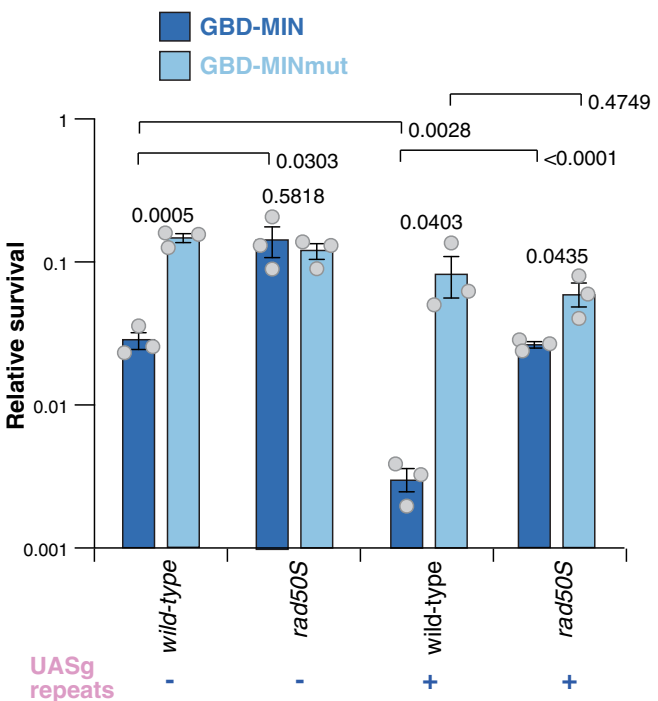

in rad50S cells. The reason for the particular length setting in these cells, which is not as high as that seen in rif2 mutants, is unclear. One possibility is that, although Tel1 activation after genotoxic stress in rad50S appears to be increased, the mutation might intrinsically impair full activation of Tel1 in the mutant complex even in the absence of Rif $2^{59}$; alternatively, the Rad50/ Rif2 interaction might be more weakly affected in vivo by the
rad50S mutation compared to the ones in MIN, although this is not supported by our biochemical data.

A role for the MIN motif at telomeres beyond Rif2. Remarkably, as described above for the Saccharomyces genus (Fig. 1a), all the yeast species analysed, which bear both Rif2 and Orc4, display the motif in Rif2, but invariably lack it in Orc4 (Fig. 6a) ${ }^{38,39}$. 
Fig. 5 Rad50S (Rad50-K81I) fails to interact with the MIN motif of Rif2. a Southern blot analysis of telomere length of Saccharomyces cerevisiae strains of the indicated genotypes, carried out as described in Fig. 2a. A quantification of hybridization signals from this gel obtained with Image Gauge v4.1 (Fuji) is shown on the right panel; strains of identical genotypes were averaged together. $\mathbf{b}$ Yeast two-hybrid assays of the S. cerevisiae fusion proteins indicated. Plates are minimal medium lacking the nutrients indicated on top. Five-fold serial dilutions were spotted left to right and incubated for $3-4$ days at $30{ }^{\circ} \mathrm{C}$. $\mathbf{c}$ Protein interaction assays with immobilized wild-type or mutant Rif2 (Rif2-min) as bait, and Rad50 or Rad50-K81I (Rad50S) proteins as prey. The bound proteins were separated by electrophoresis and detected by Western blotting (with anti-Rad50 antibody) or by Ponceau S staining (for Rif2 wild-type or Rif2-min). A representative blot is shown, as well as a quantification of three independent ones, as indicated. Data are presented as mean with SEM. $\mathbf{d}$ Viability assays of strains overexpressing a fusion protein containing the first 34 amino acids of Rif2 under control of the galactose-inducible promoter, either in wild-type form (MIN) or mutant (MINmut), as in Fig. 2b. Uninduced strains were plated onto either glucose (uninduced, top row) or induced (galactose, bottom row) medium containing the indicated chemicals and incubated at $30^{\circ} \mathrm{C}$ for $2-3$ days. e Viability assays to quantify the ability of cells to survive a double-inducible DSB on either side of the URA3 gene on chromosome $V$ were carried out as in Fig. 3b. GBD is Gal4 DNA-binding domain, MIN contains Rif2 amino acids 1-40 and the MINmut version carries the F8E P10N mutations. Relative survival was determined for three independent strains; error bars represent SEM. $P$ values are reported for each pair of datasets as indicated and were obtained with a two-tailed, unpaired $t$ test. Source data are provided as a Source Data file.

These species belong to a clade within the Saccharomycetaceae that originated after the WGD event (species in red in Fig. 6a). Instead, almost every species within the Saccharomycetaceae, which lacked Rif2, displayed the MIN-containing N-terminal region Orc4 (Fig. 6a, species in blue), with only two exceptions (species in black). A group of species within the post-WGD clade are devoid of Rif2, presumably because the duplicated ORC4 gene was lost early before it could differentiate into RIF2: these species also presented the MIN motif in Orc4. The analysis suggests that the MIN motif originated in Orc4 and that its function was then retained in Rif2 and lost from Orc4 (presumably because redundant) in the budding yeast $S$. cerevisiae and closely related species.

The proposition that the MIN motif has originated in Orc4 coupled with the suggestion that MIN in Rif2 acts to regulate the action of MRX-Tell in budding yeast raised the possibility that Orc4 might have originally had a similar role in affecting MRXTel1 before this function was taken up by Rif2. In order to test this idea, we turned to Kluyveromyces lactis, since this yeast (underlined in Fig. 6a) does not bear Rif2 and has a MIN-carrying Orc4. Similarly to budding yeast, MRX in K. lactis is required to maintain telomere length ${ }^{60}$, and mutations in the MIN motif of KlOrc4 would thus be predicted to lead to telomere elongation. We introduced the F8E and P10N mutations into KlOrc4 (orc4min) and measured telomere length in the resulting strains. Although some variation was observed, a moderate level of telomere elongation was observed in orc4-min isolates, as longer telomeres were over-represented in these strains compared to wild type (Fig. 6b). Because the $K l$ orc4-min and $S c$ rif2- $\Delta$ telomere length phenotypes are relatively minor in comparison to that enforced by the lack of Rif1 in either species (Fig. 6b) ${ }^{32}$, to further confirm the elongation phenotype of the orc4-min allele, we combined it with a null mutation in rif1, since in budding yeast disabling both the Rif1- and Rif2-dependent pathways of telomere elongation has a synergistic effect ${ }^{32}$. Indeed, combining the rif1- $\Delta$ and orc4-min mutations led to a clear additive effect on telomere elongation, indicating that Rif1 and Orc4 independently regulate telomere length in $K$. lactis, the latter protein doing so through its MIN motif. We next combined the orc4 and rif1 mutations with a mre11 deletion allele (Fig. 6b). Telomeres in the double and triple mutants were drastically shortened, indicating that MRE11 is largely epistatic to ORC4 and RIF1 in telomere length regulation in K. lactis, consistent with the idea that Orc4 MIN acts by affecting MRX-Tel1. These results suggest an unanticipated role for Orc4 at telomeres and are consistent with subfunctionalisation of the Orc4 and Rif2 proteins after the WGD event, where Orc4 has retained a function in DNA replication, while Rif2 has taken up the role in MRX-Tell control at telomeres. It remains to be established whether Orc4 has a role in
$K$. lactis telomeres as part of the ORC complex or whether it acts independently of it. As Rif2 is delivered to telomeres via the RCT of Rap1, one possibility is that Orc4 might also be recruited via an interaction with Rap1. Residues that are important in Rif2 for interaction with the $\mathrm{RCT}^{61}$ do not seem to be particularly well conserved in Orc4, and a bias towards conservation in the MINbearing Orc4 proteins is not apparent. Furthermore, some species that have an Orc4 MIN do not have a Rap1 RCT (e.g., Candida albicans). It remains therefore unclear whether the RCT of Rap1 might play a role in recruiting Orc4 at telomeres in some settings ${ }^{62}$, but we note that the role of human telomeric protein TRF2 in recruiting ORC to telomeres has been reported ${ }^{63}$. Both the dynamics and mechanism of telomere recruitment of Orc4 to fungal species will require further investigation.

In seeking to understand how general a role MIN might play in the regulation of the MRX complex, we sought to determine how widespread MIN is in ORC4 genes. Within the Saccharomycotina, the MIN motif was found to be present in the Phaffomycetaceae and CUG-Ser-1 clades, and possibly in one species within the Saccharomycodaceae (Fig. 6a, species in blue). In the Ascomycota, we failed to identify the MIN motif in any of the remaining groups within the Saccharomycotina (see four bottom clades in Fig. 6a), as well as in the two other groups, which together with the Saccharomycotina comprise this group (the Pezizomycotina-four species examined-and the Taphrinomycotina-12 species); we also could not find it in the Basidiomycota (three species) (see Fig. 1e). It therefore appears likely that the MIN motif evolved in Orc4 at some point within the Saccharomycotina, and that several species within this group lost it in Orc4 afterwards. Although we conducted searches for the motif in the genomes of some of the candidates where it would be most strongly predicted to be present, due to their belonging to clades where it is prevalent (e.g., Lachancea quebecensis and mirantina, and Candida tropicalis), we failed to find clear hits. It is unclear how the function of MIN is fulfilled at the telomeres of species that are devoid of it, but these results are consistent with the emerging remarkable modularity and flexibility of the telomeric complex in dealing with its multiple tasks (within shelterin, e.g., several differences have been documented between the human and mouse complex, reviewed in ref. $^{7}$ ).

The fission yeast Schizosaccharomyces pombe is a well-studied model system for telomere biology. When we searched for the MIN motif in S. pombe, we found a match in Taz1. In S. pombe the telomeric complex does not rely on Rap1 for binding to telomeric DNA repeats, but utilizes instead the DNA-binding protein Taz1. Remarkably, this putative MIN motif was conserved in all four Schizosaccharomyces species whose genome has been sequenced (Fig. 7a). Although several residues from the extended 

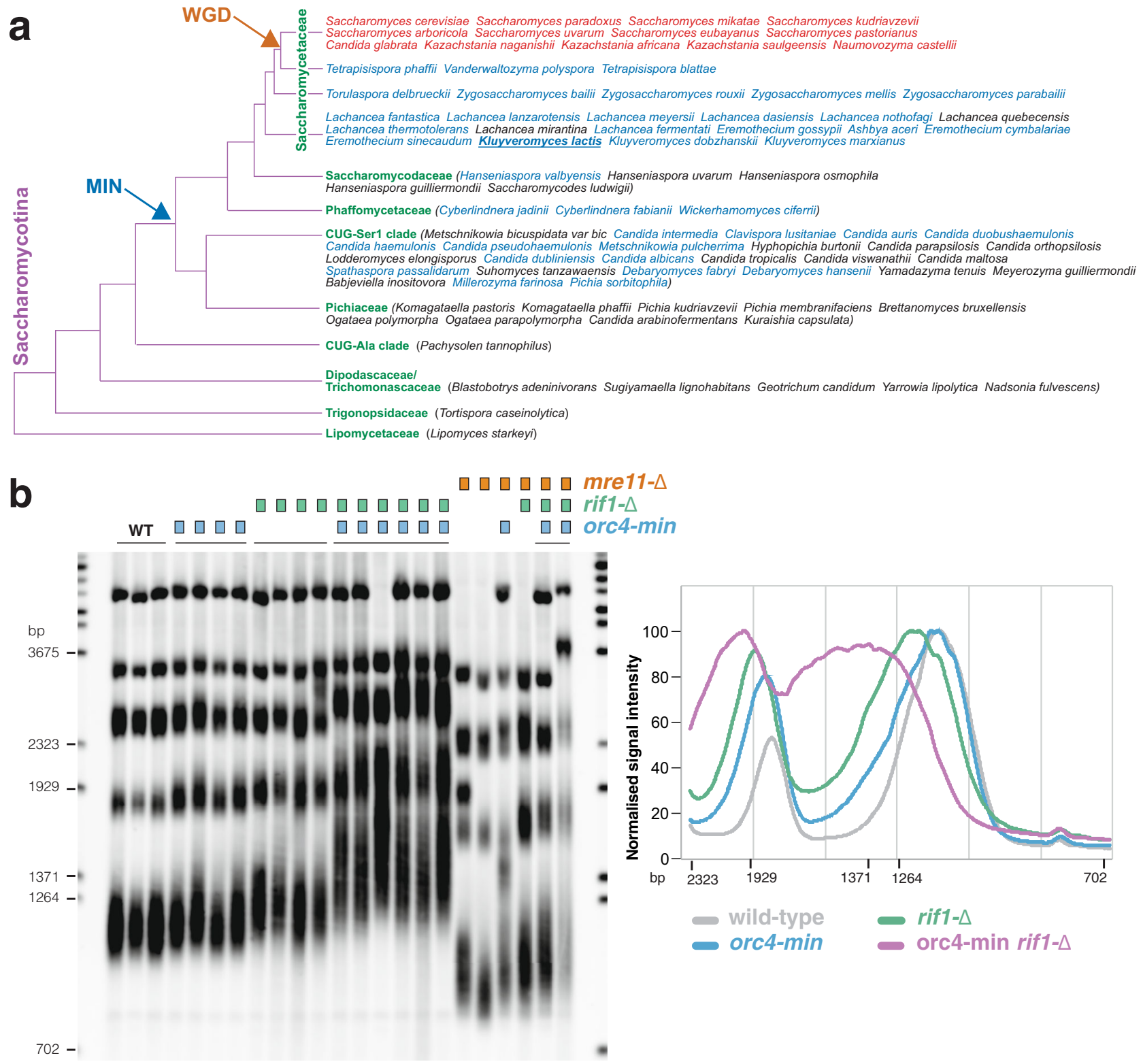

Fig. 6 The MIN motif of $\boldsymbol{K}$. lactis Orc4 suppresses telomere elongation. a Phylogenetic tree of the Saccharomycotina, adapted from ref. ${ }^{74}$. Only species for which a search for Rif2 and/Orc4 was carried out are included. Species bearing Rif2 are in red; in all cases, Rif2 has MIN domain, whereas Orc4 does not. Species bearing putative MIN domain in Orc4 are in blue, whereas those where MIN domain is not present in Orc4 are in black. All red- and bluelettered species have their MIN sequenced reported in Fig. 1b. The occurrence of the whole-genome duplication (WGD) event during the evolution of the Saccharomycetaceae clade is indicated by the orange arrow, whereas the deduced appearance of the MIN motif in Orc4 within the Saccharomycotina is indicated by the blue arrow. Kluyveromyces lactis is underlined. b Southern blotting of EcoRI-digested DNA hybridised with a telomeric oligonucleotide for the indicated genotypes. A quantification of hybridization signals from this gel obtained with Image Gauge v4.1 (Fuji) is shown on the right panel; strains of identical genotypes were averaged together. Source data are provided as a Source Data file.

consensus derived from Rif2 and Orc4 sequences, particularly in its $\mathrm{N}$-terminal region, were absent, the four invariant residues in the core motif at positions $+1,+2,+5$ and +6 (Fig. 1c) were present. The highly conserved proline at +4 was also present, and a stringent requirement seems to operate in Schizosaccharomyces at the otherwise relaxed position +3 . Intriguingly, the motif is located in the C-terminal part of the protein, in a small region of little sequence conservation outside the MIN motif itself and of no known function, which is sandwiched between the Myb/SANT DNA-binding domain and a homodimerization domain (Fig. 7b). In $S$. pombe strains carrying the same $\mathrm{F}$ to $\mathrm{E}$ and $\mathrm{P}$ to $\mathrm{N}$ mutations (taz1-min) equivalent to those characterized in S. cerevisiae, we did not observe strong changes in telomere length: this is not surprising as telomere length is not dependent on MRN-Tell in this species ${ }^{64}$. Similarly, we failed to observe strong defects in telomere protection in this mutant. In fission yeast, deprotected telomeres undergo fusions in a manner dependent on MRN when cells are kept in a prolonged G1 arrest. Strains carrying taz1-min showed no obvious effect on cell viability. This result is consistent with the major role played by Rap1 in the suppression of NHEJ in S. pombe $e^{65}$.

Because telomeres possess redundant pathways to disarm the various branches of the DDR, we hypothesise that the MIN motif in S. pombe might act redundantly with other telomere factors in dealing with the threat posed by untimely activation of MRN. We decided to address the possibility that Taz1 might target MRN by 
a

Saccharomyces_cerevisiae_Rif2/1-45 Saccharomyces_kudriavzevii_Rif2/1-45 Saccharomyces_arboricola_Rif2/1-45 Saccharomyces_uvarum_Rif $2 / 1-45$ Saccharomyces_eubayanus_Rif2/1-45 Saccharomyces_mikatae_Rif2/1-45 Saccharomyces_paradoxus_Rif2/1-45 Saccharomyces_pastorianus_Rif2/1-45 Schizosaccharomyces pombe Taz1/495-547 Schizosaccharomyces_japonicus_Taz1/519-566 Schizosaccharomyces_japonicus_Taz1/519-566 Schizosaccharomyces_cryophilus_Taz1/487
Pneumocystis_jirovecii_Taz1/235-265 Pneumocystis murina_Taz1/228-258 Pneumocystis_murina_Taz1/228-258 Pneumocystis_carinii_Taz1/225-255 Neolecta_irregularis_Taz1/ 293-336 Taphrina_deformans_Taz1/391-433 Saitoella_complicata_Taz1/490-534

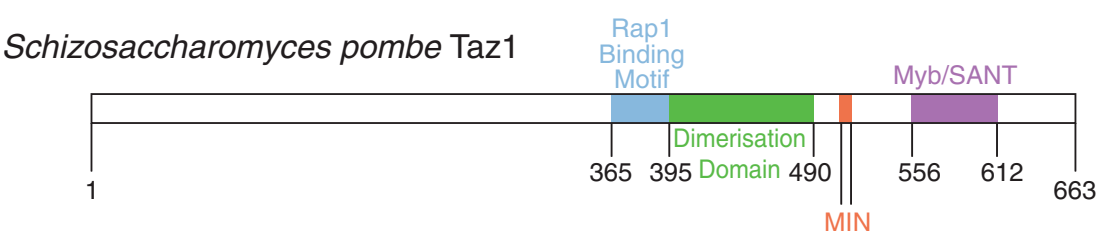

C

GBD

SpRad50

SpTaz1

SpTaz1

SpRad50

SpRad50

SpRad50

SpRad50

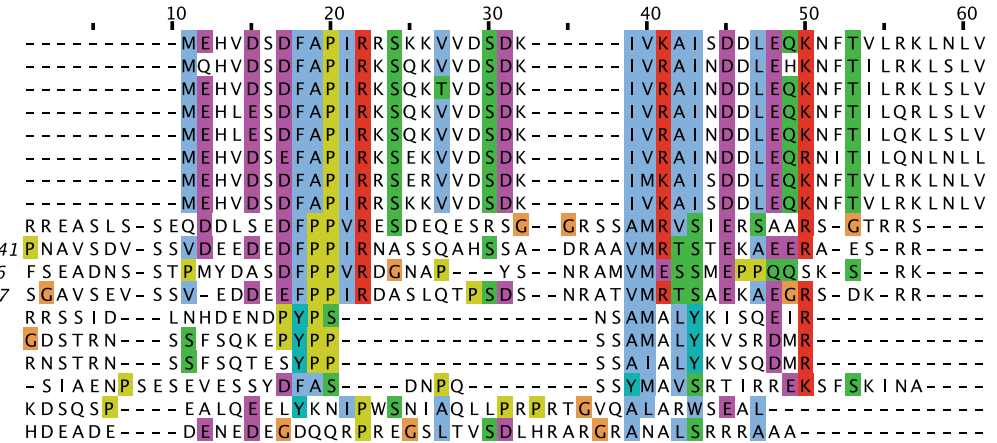

HDEADE - . DENEDEGDQQRPREGSLTVSDLHRARGRANALSRRRAAA - . . . .

\author{
$\checkmark$ \\ LV \\ LV \\ NL \\ $-$ \\ .
}

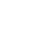




\section{Discussion}

We presented evidence that several yeast species have evolved a protein motif that has the remarkable ability to dismantle the multiple functionalities of the MRN/X complex at telomeres. The available evidence suggests that the MIN motif achieves this by promoting non-productive ATP hydrolysis by the $\mathrm{MRN} / \mathrm{X}$ complex, and thus abolishing the functions of MRN/X that depend on productive ATP hydrolysis. Our biochemical data suggest that the MIN motif appears to hijack a regulatory step normally, leading to the activation of the endonuclease activity of $\mathrm{MRN} / \mathrm{X}$ to instead disable it. Our data show that every phenotype characteristic of the rif2-null allele that we have tested is reproduced by mutating MIN within the protein. Perhaps, even more remarkably, every MRX activity that we have tested, save for exonucleolytic activity of Mre11, is disabled by MIN. Further, MIN is not just a simple binding interface tasked with the job of delivering a larger disabling activity of some sort; rather, as little as 34-40 amino acids encompassing MIN are shown to be sufficient both to bind Rad50 and to suppress DNA repair and NHEJ in vivo by MRN, and as little as 60 can inhibit Tell activation in vivo at telomeres ${ }^{38}$. How MIN achieves this remains to be determined, but is likely to shed important light on regulatory conformational transitions in $\mathrm{MRN}^{39}$. The surprising finding that Rif2 and Sae2 share a binding interface in Rad50 also points to a potential additional regulatory role for MIN in affecting Sae2 activity on MRX.

In budding yeast, the action of MRX-Tell is not only a potentially dangerous trigger for DDR activation but is also required for telomerase action, which occurs preferentially at shorter telomeres. Mre11 appears to facilitate telomerase recruitment specifically to the leading strand telomere, possibly by promoting its resection ${ }^{66}$. Remarkably, Rif 2 marks the shorter telomeres for preferential telomerase action ${ }^{67}$, so it is possible that maintaining a threshold of telomere-bound MIN motifs is required for efficient MRN inhibition. This mechanism could potentially help limit the spurious action of MIN at nontelomeric sites, where its nucleation might not reach the required threshold ${ }^{23}$. Similar considerations might apply to fission yeast telomeres, but the exact role for the Tazl MIN motif remains to be determined. We note that human cells actively recruit MRN to telomeres ${ }^{68,69}$ and that the role of ATM in telomerase activation has recently been documented ${ }^{12,13}$. In addition, MRN can have a protective role at mammalian telomeres, by preventing telomere fusions ${ }^{70,71}$. Thus, it is possible that the fine-tuning of MRN action in higher eukaryotes requires strategies similar to those allowed by the deployment of the MIN motif in yeast. Interestingly, rad50S alleles were found to lead to increased telomere fusions and genome instability in mice, raising the possibility that similar mechanisms to control MRN action at telomeres might exist in higher eukaryotes ${ }^{72}$.

\footnotetext{
Methods

Strains and plasmids. All $S$. cerevisiae $(S c)$ strains used in this study were derivatives of W303 (leu2-3,112 trp1-1 can1-100 ura3-1 ade2-1 his3-11,15). Sc and K. lactis $(K l)$ strains were grown in YPAD-rich medium or synthetic complete (SC) minimal medium $(2 \% \mathrm{w} / \mathrm{v}$ glucose, $0.67 \% \mathrm{w} / \mathrm{v}$ Yeast Nitrogen Base, $0.2 \% \mathrm{w} / \mathrm{v}$ SC dropout mix, $2 \% \mathrm{w} / \mathrm{v}$ agar, $\mathrm{pH}$ 6.0). YNB and SC mixes were from United States Biological. For transformations, the LiAc protocol was followed, with heat shock at $42{ }^{\circ} \mathrm{C}$ for $45 \mathrm{~min}$. A list of strains is provided as Supplementary Table 1.

The rif2-min allele was generated by transformation of $S c$ strains with plasmid pAB1703, which contains a small genomic RIF2 region into which the F8E P10N mutations were engineered: the plasmids were linearised with $B s r G I$ before transformation, transformants were selected on SC-ura medium and then counterselected on 5FOA-containing medium to identify recombination events that popped out the inserted plasmid from the RIF2 locus. Transformants that retained the mutations were screened by PCR using the silent BglII introduced alongside the mutations. A similar approach was used for the orc4-min allele in K. lactis using plasmid pAB2049 linearized with EcoRI
}

For overexpression of the Rif2 MIN motif in $S c$, two plasmids were used, containing the first 34 amino acids of Rif2, either in wild-type or F8E P10N form, $\mathrm{N}$ terminally fused to a GFP-binding protein fragment, expressed from a galactoseinducible promoter (pAB2081 and pAB2082, respectively). The plasmids were linearized with BstXI before being transformed into $S c$ strains. Integration of the plasmids at the HIS3 locus was confirmed by PCR

The rad50S allele was introduced in the required genetic background using pNKY349 (pAB2301) cut with BamHI-EcoRI. Correct transformants were screened by PCR and MMS sensitivity. Transformants that bore the correct plasmid integration at the RAD50 locus but retained the wild-type RAD50 allele after recombination of the construct, were also selected and used in the CPT and MMS sensitivity experiments to ensure an equal assortment of auxotrophic markers in spotting assays in RAD50 wild-type vs mutant comparisons. For the NHEJ experiments, a variant of the pNKY349 plasmid where the URA4 marker was swapped with HIS3 was constructed, pScRad50-K81I-Hi (pAB2304), and used in the same way.

Southern blotting analysis. $S c$ or $K l$ genomic DNA was prepared from $10 \mathrm{ml}$ log phase cultures in YPAD-rich media by vortexing cell pellets with $0.3 \mathrm{~g}$ glass beads in $0.4 \mathrm{ml} 2 \%$ Triton $\mathrm{X}, 1 \%$ sodium dodecyl sulfate (SDS), $100 \mathrm{mM} \mathrm{NaCl}, 10 \mathrm{mM}$ Tris- $\mathrm{HCl} \mathrm{pH}$ 8.0, $1 \mathrm{mM}$ ethylenediaminetetraacetic acid (EDTA) $\mathrm{pH}$ 8.0, followed by phenol:chloroform:isoamyl alcohol (25:24:1) extraction, ethanol precipitation and RNase A digestion. For telomere length analysis, $1 \mu \mathrm{g}$ of genomic DNA was digested with XhoI (S. cerevisiae) or EcoRI $(K l)$ overnight and gel electrophoresis was carried out on $1 \%$ agarose gels. Depurination was carried out by soaking the gel in $125 \mathrm{mM} \mathrm{HCl}$ for $10 \mathrm{~min}$, followed by denaturation in $0.5 \mathrm{M} \mathrm{NaOH} 1.5 \mathrm{M}$ $\mathrm{NaCl}$ for $30 \mathrm{~min}$. The overnight transfer was in $20 \times$ saline sodium citrate (SSC) using nylon membranes (Roche). After ultraviolet crosslinking, membranes were incubated at $60^{\circ} \mathrm{C}(\mathrm{Sc})$ or $50^{\circ} \mathrm{C}(\mathrm{Kl})$ in $5 \times \mathrm{SSC}, 5 \%$ dextran sulfate, $0.2 \%$ I-Block (Thermo Fisher T2015) and $0.1 \%$ SDS. DNA probes were briefly denatured before being added, and hybridization was carried out overnight. Washes were at room temperature with buffers pre-heated at $60^{\circ} \mathrm{C}(S c)$ or $50^{\circ} \mathrm{C}(K l)$ twice in $1 \times$ SSC $0.1 \%$ SDS and then twice in $0.5 \times$ SSC $0.1 \%$ SDS. Detection was by incubation for 1 $\mathrm{h}$ at room temperature (RT) in $100 \mathrm{mM}$ Tris $\mathrm{pH} 7.55,150 \mathrm{mM} \mathrm{NaCl}, 1 \%$ skimmed milk, plus $1 \mu \mathrm{l}$ of alkaline phosphatase-tagged anti-fluorescein $\mathrm{F}(\mathrm{ab})$ (Roche) $(1: 125,000)$, followed by four washes at RT in $100 \mathrm{mM}$ Tris $\mathrm{pH} 7.55,150 \mathrm{mM} \mathrm{NaCl}$, and detection with CDP-Star detection agent. Imaging was on a LAS4000 instrument. Probes were made either by PCR of a $\mathrm{Y}^{\prime}$ fragment followed by random priming $(S c)$ or by terminal transferase extension of a 25 -mer telomeric oligonucleotide $(K l)$, both in the presence of Fl-dUTP. Southern data were collected using an Image Quant LAS4000 instrument (GE), images were processed using Adobe Photoshop and lanes were analysed using Image Gauge v4.1 (Fuji).

Single-cell checkpoint arrest analysis. Strains were grown overnight in $5 \mathrm{ml}$ of YPLG (acid lactic and glycerol) medium. The following morning, cells were diluted into $5 \mathrm{ml}$ of the same medium to $3 \times 10^{5}$ cells $/ \mathrm{ml}$ and incubated at $30^{\circ} \mathrm{C}$. After $2 \mathrm{~h}$ of incubation, $1 \mathrm{ml}$ of $20 \%$ galactose was added in order to induce the $\mathrm{HO}$ endonuclease gene and the strains were incubated for a further $2 \mathrm{~h}$. After that, the cells were plated down in the central line of a YPAD plate, kept previously at room temperature. Then, small-budded cells were dissected into a grid by a micromanipulator for analysis. After $1 \mathrm{~h}$ from the beginning of the dissection, cells were checked every $30 \mathrm{~min}$ for the second round of budding in order to record the cell cycle restart. YPAD plates were preserved at $30^{\circ} \mathrm{C}$ in an incubator between observations. After the growth of the colonies at $30^{\circ} \mathrm{C}$, the following day, the central line of the plate was removed and it was incubated for a further one day. The next morning, the strains were replicated in Sc-Lys plate and incubated for 2 days at $30^{\circ} \mathrm{C}$. In the end, Lys ${ }^{+}$colonies were excluded from the dataset because the LYS2 gene is located on the telomere-proximal side of the HO site and only cells Lys ${ }^{-}$that had been subjected to a DNA break were scored. The average restart time for each construct was estimated using Kaplan-Meier survival analysis in GraphPad.

NHEJ assays. Strains were grown on a solid minimal medium containing glucose and lacking uracil and tryptophan, and then grown to saturation in the same medium overnight, before being diluted and plated on the same plates (to calculate plating efficiency, used for normalisation), and also on minimal plates lacking tryptophan and containing glucose $\mathrm{e}^{33}$

Yeast two-hybrid analysis. Yeast two-hybrid assays were performed by cotransforming GBD and GAD (Gal4-activating domain) plasmids (in the pGBKT7 and pGADT7 vectors) in various combinations in the PJ69-4A budding yeast strain (MATa trp1-901 leu2-3,112 ura3-52 his3-200 gal4 gal80 LYS2::GAL1-HIS3 GAL2ADE2 met2::GAL7-lacZ). Transformants were screened for interaction by spotting 5 -fold dilutions on minimal plates lacking tryptophan and leucine for selection of GBD and GAD plasmids, respectively. Interactions were assessed by quantification of the expression of the HIS3 and ADE2 markers by plating on minimal medium lacking, in addition, histidine or adenine. The stringency of the HIS3 reporter was also increased by the addition of $3 \mathrm{mM} 3$-aminotriazole. The plates were then 
incubated at $30^{\circ} \mathrm{C}$ for 3 (SC-leu-trp) or 4 (selective plates) days, imaged with a Syngene InGenius instrument and processed with Photoshop.

Recombinant protein purification. Saccharomyces cerevisiae Mre11-Rad50-Xrs2 (MRX, containing Mre11-his, Xrs2-FLAG and untagged Rad50), Mre11-Rad50 (MR, containing Mre11-his and untagged Rad50), Mrell (his-tagged at the C terminus), Rad50 (FLAG-tagged at the C terminus), Rad50S (K81I, FLAG-tagged at the $\mathrm{C}$ terminus) and Xrs2 (FLAG-tagged at the $\mathrm{C}$ terminus) proteins were prepared after expression in Spodoptera frugiperda 9 (Sf9) cells by affinity chromatography $28,51,52,73$. Recombinant phosphorylated Sae2, containing an MBP tag at the $\mathrm{N}$ terminus and a His-tag at the $\mathrm{C}$ terminus, was expressed in $S f 9$ cells and purified by sequential affinity chromatography steps using amylose resin (New England Biolabs), followed by the cleavage of the MBP tag with PreScission protease (12 $\mu \mathrm{g}$ of protease per $100 \mu \mathrm{g}$ MBP-Sae2-His). Finally, pSae2 was purified using NiNTA agarose (Qiagen) ${ }^{52}$.

Wild-type Rif2 and Rif2-min variants were expressed using pFB-MBP-Rif2-his or pFB-MBP-Rif2-min-his vectors, respectively. The $S f 9$ cell pellets (from $1000 \mathrm{ml}$ culture) were resuspended in 4 volumes of lysis buffer $(50 \mathrm{mM}$ Tris- $\mathrm{HCl} \mathrm{pH} \mathrm{7.5,} 1$ $\mathrm{mM}$ dithiothreitol, $1 \mathrm{mM}$ EDTA, 1:400 Sigma protease inhibitory cocktail P8340, 1 $\mathrm{mM}$ phenylmethylsulfonyl fluoride, $30 \mu \mathrm{g} / \mathrm{ml}$ leupeptin) and incubated for $20 \mathrm{~min}$ at $4{ }^{\circ} \mathrm{C}$. One-half volume of $50 \%$ glycerol and $6.5 \%$ volume $5 \mathrm{M} \mathrm{NaCl}$ solutions were then added, and the sample was incubated for $30 \mathrm{~min}$ while stirring. The cell extract was centrifuged $(48,000 \times g$ for $30 \mathrm{~min})$ to obtain the soluble extract. The extract was bound to $6 \mathrm{ml}$ amylose resin (New England Biolabs) for $1 \mathrm{~h}$ batchwise. The resin was washed with wash buffer $(50 \mathrm{mM}$ Tris- $\mathrm{HCl} \mathrm{pH} \mathrm{7.5,} 5 \mathrm{mM} \mathrm{2-}$ mercaptoethanol, $1 \mathrm{M} \mathrm{NaCl}, 10 \%$ glycerol, $1 \mathrm{mM}$ phenylmethylsulfonyl fluoride), and protein was eluted with elution buffer $(50 \mathrm{mM}$ Tris- $\mathrm{HCl} \mathrm{pH} \mathrm{7.5,5 \textrm {mM } 2 -}$ mercaptoethanol, $300 \mathrm{mM} \mathrm{NaCl}, 10 \%$ glycerol, $1 \mathrm{mM}$ phenylmethylsulfonyl fluoride, $10 \mathrm{mM}$ maltose). The protein concentration was estimated by the Bradford method and PreScission protease $(1: 5, \mathrm{w} / \mathrm{w})$ was added, and the sample was incubated for $2 \mathrm{~h}$ at $4{ }^{\circ} \mathrm{C}$. Then, $10 \mathrm{mM}$ imidazole (final concentration) was added to the sample and the solution was bound to $0.5 \mathrm{ml}$ NiNTA resin (Qiagen). The resin was washed with NTA buffer A1 $(50 \mathrm{mM}$ Tris- $\mathrm{HCl} \mathrm{pH} \mathrm{7.5,5} \mathrm{mM} \mathrm{2-}$ mercaptoethanol, $1 \mathrm{M} \mathrm{NaCl}, 10 \%$ glycerol, $0.5 \mathrm{mM}$ phenylmethylsulfonyl fluoride, $58 \mathrm{mM}$ imidazole) and NTA wash buffer A2 (50 mM Tris- $\mathrm{HCl} \mathrm{pH} \mathrm{7.5,} 5 \mathrm{mM} 2$ mercaptoethanol, $150 \mathrm{mM} \mathrm{NaCl}, 10 \%$ glycerol, $58 \mathrm{mM}$ imidazole) and eluted with NTA buffer B (50 mM Tris-HCl pH 7.5, $5 \mathrm{mM}$ 2-mercaptoethanol, $150 \mathrm{mM} \mathrm{NaCl}$, $10 \%$ glycerol, $300 \mathrm{mM}$ imidazole). The eluate was dialysed into $50 \mathrm{mM}$ Tris- $\mathrm{HCl}$ pH 7.5, 5 mM 2-mercaptoethanol, $150 \mathrm{mM} \mathrm{NaCl}, 10 \%$ glycerol, aliquoted, frozen in liquid nitrogen and stored at $-80^{\circ} \mathrm{C}$. The purification yielded $\sim 1 \mathrm{ml}$ of $10 \mu \mathrm{M}$ Rif2 (his-tagged at the $\mathrm{C}$ terminus). The Rif2-min variant was prepared in the same way.

ATPase assays. The reaction buffer contained $25 \mathrm{mM}$ Tris-acetate $\mathrm{pH} 7.5,5 \mathrm{mM}$ magnesium acetate, $1 \mathrm{mM}$ dithiothreitol, $0.25 \mathrm{mg} / \mathrm{ml}$ bovine serum albumin (BSA) (New England Biolabs), $150 \mu \mathrm{M}$ cold ATP, $1 \mathrm{nM}$ labelled $\gamma_{-}{ }^{32} \mathrm{P}-\mathrm{ATP}, 50 \mathrm{nM}$ DNA substrate (in molecules, annealed oligonucleotides 210-GTAAGTGCCGCGGTGC GGGTGCCAGGGCGTGCCCTTGGGCTCCCCGGGCGCGTACTCCACCTCA TGCATC and 211-GATGCATGAGGTGGAGTACGCGCCCGGGGAGCCCAA GGGCACGCCCTGGCACCCGCACCGCGGCACTTAC) and respective recombinant proteins. The reactions were incubated for $4 \mathrm{~h}$ at $30^{\circ} \mathrm{C}$. The reactions were stopped with EDTA ( $50 \mathrm{mM}$ final concentration). The substrate and hydrolysed ATP were separated by thin-layer chromatography using $0.3 \mathrm{M}$ lithium chloride and $0.3 \mathrm{M}$ formic acid (mixed 1:1) as the mobile phase. The plates were then dried and exposed to storage phosphor screens and a signal was detected using Typhoon imager (GE Healthcare)

Nuclease assays. The 50-bp-long DNA substrate was prepared by annealing oligonucleotides PC1253C (AACGTCATAGACGATTACATTGCTAGGACA TCTTTGCCCACGTTGACCCA) and PC1253B (TGGGTCAACGTGGGCAAAG ATGTCCTAGCAATGTAATCGTCTATGACGTT) with $3^{\prime}$-terminal biotin ${ }^{28}$. Upon labelling with ${ }^{32} \mathrm{P}$, annealing and purification, the substrate was bound to streptavidin to create a protein block. The buffer for the nuclease assays contained $25 \mathrm{mM}$ Tris-acetate $\mathrm{pH}$ 7.5, $1 \mathrm{mM}$ dithiothreitol, $0.25 \mathrm{mg} / \mathrm{ml} \mathrm{BSA}$ (New England Biolabs), $1 \mathrm{nM}$ DNA substrate (in molecules), $5 \mathrm{mM}$ magnesium acetate, $1 \mathrm{mM}$ manganese acetate, $1 \mathrm{mM}$ ATP, $80 \mathrm{Us} / \mathrm{ml}$ pyruvate kinase, $1 \mathrm{mM}$ phosphoenolpyruvate and the recombinant proteins, as indicated. The assays were incubated for $30 \mathrm{~min}$ at $4{ }^{\circ} \mathrm{C}$, and the reaction products were analysed by electrophoresis under denaturing conditions and autoradiography.

Electrophoretic mobility shift assays. To monitor DNA binding, assays $(15 \mu \mathrm{l})$ were carried out in $25 \mathrm{mM}$ Tris-acetate $\mathrm{pH} 7.5,1 \mathrm{mM}$ dithiothreitol, $5 \mathrm{mM}$ magnesium acetate, $1 \mathrm{mM}$ manganese acetate, $0.25 \mathrm{mg} / \mathrm{ml}$ BSA (New England Biolabs), $1 \mathrm{mM}$ phosphoenolpyruvate, $1 \mathrm{mM}$ ATP, $80 \mathrm{U} / \mathrm{ml}$ pyruvate kinase and $1 \mathrm{nM}{ }^{32} \mathrm{P}$ labelled dsDNA substrate (in molecules, annealed oligonucleotides PC1253C and

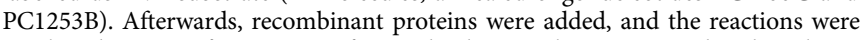
incubated at $30^{\circ} \mathrm{C}$ for $30 \mathrm{~min}$. Afterwards, the samples were mixed with $4 \mu \mathrm{l} 50 \%$ glycerol with bromophenol blue, and separated by electrophoresis in $6 \%$ polyacrylamide in TAE buffer. Gels were dried and developed by autoradiography.
Pull-down assays. The $S f 9$ cell lysate containing $\sim 5 \mu \mathrm{g}$ of MBP-Rif2 or MBP-Rif2min (see recombinant protein preparation) was incubated for $1 \mathrm{~h}$ at $4{ }^{\circ} \mathrm{C}$ with amylose resin (New England Biolabs, $50 \mu$ per reaction). The resin with the immobilized MBP-Rif2 variants was washed five times with $1 \mathrm{ml}$ wash buffer (50 $\mathrm{mM}$ Tris- $\mathrm{HCl} \mathrm{pH}$ 7.5, $200 \mathrm{mM} \mathrm{NaCl}, 0.2 \% \mathrm{NP} 40,2 \mathrm{mM}$ EDTA, Sigma protease inhibitory cocktail P8340 1:1000), using $500 \times g$ for 2 min centrifugation each time to pellet the resin. Afterwards, $1 \mu \mathrm{g}$ of Mre11, $500 \mathrm{ng}$ of Rad50, or $1 \mu \mathrm{g}$ of Xrs2 were added to the resin and incubated together for $1 \mathrm{~h}$ in the same wash buffer. Afterwards, the resin was washed four times with $1 \mathrm{ml}$ wash buffer to remove unbound proteins. Bound proteins were then eluted with $100 \mu \mathrm{l}$ wash buffer supplemented with $20 \mathrm{mM}$ maltose. PreScission protease was then added $(0.5 \mu \mathrm{g})$ to cleave the MBP tag from MBP-Rif2 or MBP-Rif2-min. The proteins in the eluate were separated by electrophoresis and detected by Western blotting. The antibodies used were: anti-yRad50 (Thermo Scientific, PA5-32176, 1:1000); anti-FLAG (Sigma, F3165, 1:1000); anti-His (MBL, D291-3, 1:5000). Pull-down assays with the Rad50-K81I variant were carried out as above with the following modifications: the resin with the immobilized MBP-Rif2 variants was first washed four times with 1

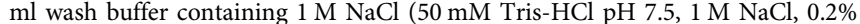
NP40, 2 mM EDTA, Sigma protease inhibitory cocktail P8340 1:1000), and then once with the same buffer but containing $150 \mathrm{mM} \mathrm{NaCl}$. Afterwards, $750 \mathrm{ng}$ of recombinant Rad50 or Rad50-K81I were added to the resin and incubated for $1 \mathrm{~h}$ at $4{ }^{\circ} \mathrm{C}$ in wash buffer containing $150 \mathrm{mM} \mathrm{NaCl}$. The same buffer was then used in washes to remove the unbound proteins, as described above.

Statistics and reproducibility. All DNA and protein gels were repeated at least twice with similar results. Yeast two-hybrid assays were conducted with pools of transformants. Measurements were taken from distinct samples.

Reporting summary. Further information on research design is available in the Nature Research Reporting Summary linked to this article.

\section{Data availability}

The data supporting the findings of this study are available from the corresponding authors upon reasonable request. Uncropped images of gels, blots and spot assays are provided with this paper. Source data are provided with this paper.

Received: 24 July 2020; Accepted: 29 May 2021;

Published online: 22 June 2021

\section{References}

1. Roake, C. M. \& Artandi, S. E. Regulation of human telomerase in homeostasis and disease. Nat. Rev. Mol. Cell Biol. 21, 384-397 (2020).

2. Lazzerini-Denchi, E. \& Sfeir, A. Stop pulling my strings - what telomeres taught us about the DNA damage response. Nat. Rev. Mol. Cell Biol. 17, 364-378 (2016).

3. Nugent, C. I. et al. Telomere maintenance is dependent on activities required for end repair of double-strand breaks. Curr. Biol. 8, 657-660 (1998).

4. Dahlen, M., Olsson, T., Kanter-Smoler, G., Ramne, A. \& Sunnerhagen, P. Regulation of telomere length by checkpoint genes in Schizosaccharomyces pombe. Mol. Biol. Cell 9, 611-621 (1998).

5. Boulton, S. J. \& Jackson, S. P. Identification of a Saccharomyces cerevisiae Ku80 homologue: roles in DNA double strand break rejoining and in telomeric maintenance. Nucleic Acids Res. 24, 4639-4648 (1996).

6. Porter, S. E., Greenwell, P. W., Ritchie, K. B. \& Petes, T. D. The DNA-binding protein Hdflp (a putative $\mathrm{Ku}$ homologue) is required for maintaining normal telomere length in Saccharomyces cerevisiae. Nucleic Acids Res. 24, 582-585 (1996).

7. de Lange, T. Shelterin-mediated telomere protection. Annu. Rev. Genet. 52, 223-247 (2018)

8. de Lange, T. How telomeres solve the end-protection problem. Science 326, 948-952 (2009).

9. Lustig, A. J. \& Petes, T. D. Identification of yeast mutants with altered telomere structure. Proc. Natl Acad. Sci. USA 83, 1398-1402 (1986).

10. Kironmai, K. M. \& Muniyappa, K. Alteration of telomeric sequences and senescence caused by mutations in RAD50 of Saccharomyces cerevisiae. Genes Cells 2, 443-455 (1997).

11. Naito, T., Matsuura, A. \& Ishikawa, F. Circular chromosome formation in a fission yeast mutant defective in two ATM homologues. Nat. Genet 20, 203-206 (1998).

12. Lee, S. S., Bohrson, C., Pike, A. M., Wheelan, S. J. \& Greider, C. W. ATM kinase is required for telomere elongation in mouse and human cells. Cell Rep. 13, 1623-1632 (2015).

13. Tong, A. S. et al. ATM and ATR signaling regulate the recruitment of human telomerase to telomeres. Cell Rep. 13, 1633-1646 (2015). 
14. Syed, A. \& Tainer, J. A. The MRE11-RAD50-NBS1 complex conducts the orchestration of damage signaling and outcomes to stress in dna replication and repair. Annu. Rev. Biochem. 87, 263-294 (2018).

15. Nakada, D., Matsumoto, K. \& Sugimoto, K. ATM-related Tel1 associates with double-strand breaks through an Xrs2-dependent mechanism. Genes Dev. 17, 1957-1962 (2003).

16. You, Z., Chahwan, C., Bailis, J., Hunter, T. \& Russell, P. ATM activation and its recruitment to damaged dna require binding to the $\mathrm{C}$ terminus of $\mathrm{Nbs} 1$. Mol. Cell Biol. 25, 5363-5379 (2005).

17. Falck, J., Coates, J. \& Jackson, S. P. Conserved modes of recruitment of ATM, ATR and DNA-PKcs to sites of DNA damage. Nature 434, 605-611 (2005).

18. Lammens, K. et al. The Mre11:Rad50 structure shows an ATP-dependent molecular clamp in DNA double-strand break repair. Cell 145, 54-66 (2011).

19. Deshpande, R. A., Lee, J. H. \& Paull, T. T. Rad50 ATPase activity is regulated by DNA ends and requires coordination of both active sites. Nucleic Acids Res. 45, 5255-5268 (2017).

20. Deshpande, R. A. et al. ATP-driven Rad50 conformations regulate DNA tethering, end resection, and ATM checkpoint signaling. EMBO J. 33, 482-500 (2014).

21. Hopfner, K. P. et al. Structural biology of Rad50 ATPase: ATP-driven conformational control in DNA double-strand break repair and the ABCATPase superfamily. Cell 101, 789-800 (2000).

22. Reis, C. C., Batista, S. \& Ferreira, M. G. The fission yeast MRN complex tethers dysfunctional telomeres for NHEJ repair. EMBO J. 31, 4576-4586 (2012).

23. Cassani, C. et al. Tel1 and Rif2 regulate MRX functions in end-tethering and repair of DNA double-strand breaks. PLoS Biol. 14, e1002387 (2016).

24. Lee, J.-H. et al. Ataxia telangiectasia-mutated (ATM) kinase activity is regulated by ATP-driven conformational changes in the Mre11/Rad50/Nbs1 (MRN) complex. J. Biol. Chem. 288, 12840-12851 (2013).

25. Hailemariam, S., Kumar, S. \& Burgers, P. M. Activation of Tel1 ATM kinase requires Rad50 ATPase and long nucleosome-free DNA, but no DNA ends. J. Biol. Chem. 294, 10120-10130 (2019).

26. Käshammer, L. et al. Mechanism of DNA end sensing and processing by the Mre11-Rad50 complex. Mol. Cell 76, 382-394.e6 (2019).

27. Liu, Y. et al. ATP-dependent DNA binding, unwinding, and resection by the Mre11/Rad50 complex. EMBO J. 35, 743-758 (2016).

28. Cannavo, E. \& Cejka, P. Sae2 promotes dsDNA endonuclease activity within Mre11-Rad50-Xrs2 to resect DNA breaks. Nature 514, 122-125 (2014).

29. Shibata, A. et al. DNA double-strand break repair pathway choice is directed by distinct MRE11 nuclease activities. Mol. Cell 53, 7-18 (2014).

30. Rai, R. et al. NBS1 phosphorylation status dictates repair choice of dysfunctional telomeres. Mol. Cell 65, 801-817 (2017). e4.

31. Doksani, Y., Wu, J. Y., de Lange, T. \& Zhuang, X. Super-resolution fluorescence imaging of telomeres reveals TRF2-dependent T-loop formation. Cell 155, 345-356 (2013)

32. Wotton, D. \& Shore, D. A novel Rap1p-interacting factor, Rif2p, cooperates with Riflp to regulate telomere length in Saccharomyces cerevisiae. Genes Dev. 11, 748-760 (1997).

33. Marcand, S., Pardo, B., Gratias, A., Cahun, S. \& Callebaut, I. Multiple pathways inhibit NHEJ at telomeres. Genes Dev. 22, 1153-1158 (2008).

34. Viscardi, V., Baroni, E., Romano, M., Lucchini, G. \& Longhese, M. P. Sudden telomere lengthening triggers a Rad53-dependent checkpoint in Saccharomyces cerevisiae. Mol. Biol. Cell 14, 3126-3143 (2003).

35. Craven, R. J. \& Petes, T. D. Dependence of the regulation of telomere length on the type of subtelomeric repeat in the yeast Saccharomyces cerevisiae. Genetics 152, 1531-1541 (1999).

36. Bonetti, D., Clerici, M., Manfrini, N., Lucchini, G. \& Longhese, M. P. The MRX complex plays multiple functions in resection of Yku- and Rif2protected DNA ends. PLoS ONE 5, e14142 (2010).

37. Hirano, Y., Fukunaga, K. \& Sugimoto, K. Rif1 and rif2 inhibit localization of tell to DNA ends. Mol. Cell 33, 312-322 (2009).

38. Kaizer, H., Connelly, C. J., Bettridge, K., Viggiani, C. \& Greider, C. W. Regulation of telomere length requires a conserved N-terminal domain of Rif2 in Saccharomyces cerevisiae. Genetics 201, 573-586 (2015).

39. Hailemariam, S. et al. The telomere-binding protein Rif 2 and ATP-bound Rad50 have opposing roles in the activation of yeast Tel1 ${ }^{\text {ATM }}$ kinase. J. Biol. Chem. 294, 18846-18852 (2019).

40. Wolfe, K. H. \& Shields, D. C. Molecular evidence for an ancient duplication of the entire yeast genome. Nature 387, 708-713 (1997).

41. Ma, Y. \& Greider, C. W. Kinase-independent functions of TEL1 in telomere maintenance. Mol. Cell Biol. 29, 5193-5202 (2009).

42. Shima, H., Suzuki, M. \& Shinohara, M. Isolation and characterization of novel xrs2 mutations in Saccharomyces cerevisiae. Genetics 170, 71-85 (2005).

43. Sabourin, M., Tuzon, C. T. \& Zakian, V. A. Telomerase and Tellp preferentially associate with short telomeres in S. cerevisiae. Mol. Cell 27, 550-561 (2007).
44. Martina, M. et al. A balance between Tel1 and Rif2 activities regulates nucleolytic processing and elongation at telomeres. Mol. Cell Biol. 32, 1604-1617 (2012)

45. Yu, T. Y., Garcia, V. E. \& Symington, L. S. CDK and Mec1/Tel1-catalyzed phosphorylation of Sae2 regulate different responses to DNA damage. Nucleic Acids Res. 47, 11238-11249 (2019).

46. Menin, L. et al. Tel1/ATM prevents degradation of replication forks that reverse after topoisomerase poisoning. EMBO Rep. 19, e45535 (2018).

47. Bonetti, D. et al. Shelterin-like proteins and Yku inhibit nucleolytic processing of Saccharomyces cerevisiae telomeres. PLoS Genet. 6, e1000966 (2010).

48. Ribeyre, C. \& Shore, D. Anticheckpoint pathways at telomeres in yeast. Nat. Struct. Mol. Biol. 19, 307-313 (2012).

49. Michelson, R. J., Rosenstein, S. \& Weinert, T. A telomeric repeat sequence adjacent to a DNA double-stranded break produces an anticheckpoint. Genes Dev. 19, 2546-2559 (2005).

50. Trujillo, K. M. \& Sung, P. DNA structure-specific nuclease activities in the Saccharomyces cerevisiae Rad50*Mre11 complex. J. Biol. Chem. 276, 35458-35464 (2001).

51. Cannavo, E., Reginato, G. \& Cejka, P. Stepwise $5^{\prime}$ DNA end-specific resection of DNA breaks by the Mre11-Rad50-Xrs2 and Sae2 nuclease ensemble. Proc. Natl Acad. Sci. USA 116, 5505-5513 (2019).

52. Cannavo, E. et al. Regulatory control of DNA end resection by Sae2 phosphorylation. Nat. Commun. 9, 4016 (2018).

53. Cassani, C. et al. The ATP-bound conformation of the Mre11-Rad50 complex is essential for Tel1/ATM activation. Nucleic Acids Res. 47, 3550-3567 (2019)

54. Chen, L. et al. Effect of amino acid substitutions in the rad50 ATP binding domain on DNA double strand break repair in yeast. J. Biol. Chem. 280, 2620-2627 (2005).

55. Alani, E., Padmore, R. \& Kleckner, N. Analysis of wild-type and rad50 mutants of yeast suggests an intimate relationship between meiotic chromosome synapsis and recombination. Cell 61, 419-436 (1990).

56. Mimitou, E. P. \& Symington, L. S. DNA end resection: many nucleases make light work. DNA Rep. 8, 983-995 (2009).

57. Moreau, S., Ferguson, J. R. \& Symington, L. S. The nuclease activity of Mre11 is required for meiosis but not for mating type switching, end joining, or telomere maintenance. Mol. Cell Biol. 19, 556-566 (1999).

58. Bonetti, D., Martina, M., Clerici, M., Lucchini, G. \& Longhese, M. P. Multiple pathways regulate $3^{\prime}$ overhang generation at S. cerevisiae telomeres. Mol. Cell 35, 70-81 (2009).

59. Yu, T. Y., Kimble, M. T. \& Symington, L. S. Sae2 antagonizes Rad9 accumulation at DNA double-strand breaks to attenuate checkpoint signaling and facilitate end resection. Proc. Natl Acad. Sci. USA 115, E11961-E11969 (2018).

60. Carter, S. D., Iyer, S., Xu, J., McEachern, M. J. \& Astrom, S. U. The role of nonhomologous end-joining components in telomere metabolism in Kluyveromyces lactis. Genetics 175, 1035-1045 (2007).

61. Shi, T. et al. Rif1 and Rif2 shape telomere function and architecture through multivalent Rap1 interactions. Cell 153, 1340-1353 (2013).

62. Lue, N. F. Plasticity of telomere maintenance mechanisms in yeast. Trends Biochem. Sci. 35, 8-17 (2010).

63. Deng, Z., Norseen, J., Wiedmer, A., Riethman, H. \& Lieberman, P. M. TERRA RNA binding to TRF2 facilitates heterochromatin formation and ORC recruitment at telomeres. Mol. Cell 35, 403-413 (2009).

64. Nakamura, T. M., Moser, B. A. \& Russell, P. Telomere binding of checkpoint sensor and DNA repair proteins contributes to maintenance of functional fission yeast telomeres. Genetics 161, 1437-1452 (2002).

65. Pan, L., Hildebrand, K., Stutz, C., Thomä, N. \& Baumann, P. Minishelterins separate telomere length regulation and end protection in fission yeast. Genes Dev. 29, 1164-1174 (2015).

66. Faure, V., Coulon, S., Hardy, J. \& Geli, V. Cdc13 and telomerase bind through different mechanisms at the lagging- and leading-strand telomeres. Mol. Cell 38, 842-852 (2010)

67. McGee, J. S. et al. Reduced Rif2 and lack of Mec1 target short telomeres for elongation rather than double-strand break repair. Nat. Struct. Mol. Biol. 17, 1438-1445 (2010)

68. Zhu, X. D., Küster, B., Mann, M., Petrini, J. H. \& de Lange, T. Cell-cycleregulated association of RAD50/MRE11/NBS1 with TRF2 and human telomeres. Nat. Genet. 25, 347-352 (2000).

69. Okamoto, K. et al. A two-step mechanism for TRF2-mediated chromosomeend protection. Nature 494, 502-505 (2013).

70. Dimitrova, N. \& de Lange, T. Cell cycle-dependent role of MRN at dysfunctional telomeres: ATM signaling-dependent induction of nonhomologous end joining (NHEJ) in G1 and resection-mediated inhibition of NHEJ in G2. Mol. Cell Biol. 29, 5552-5563 (2009).

71. Deng, Y., Guo, X., Ferguson, D. O. \& Chang, S. Multiple roles for MRE11 at uncapped telomeres. Nature 460, 914-918 (2009).

72. Bender, C. F. et al. Cancer predisposition and hematopoietic failure in Rad50 (S/S) mice. Genes Dev. 16, 2237-2251 (2002). 
73. Oh, J., Al-Zain, A., Cannavo, E., Cejka, P. \& Symington, L. S. Xrs2 dependent and independent functions of the Mre11-Rad50 complex. Mol. Cell 64, 405-415 (2016).

74. Shen, X. X. et al. Tempo and mode of genome evolution in the budding yeast subphylum. Cell 175, 1533-1545.e20 (2018).

75. Milo, S., Harari-Misgav, R., Hazkani-Covo, E. \& Covo, S. Limited DNA repair gene repertoire in ascomycete yeast revealed by comparative genomics. Genome Biol. Evol. 11, 3409-3423 (2019).

76. Chen, Y. et al. A conserved motif within RAP1 has diversified roles in telomere protection and regulation in different organisms. Nat. Struct. Mol. Biol. 18, 213-221 (2011).

\section{Acknowledgements}

We thank Lorraine Symington, David Shore, Jürgen Heinisch, Dudy Tzfati, Stephane Marcand, Stefan Åström and Miki Shinohara for the gift of strains and plasmids; Matt Neale for help with telomere blot quantification; Marta Grillo, Craig Gazzard, Romeela Joseph, Rebecca Leask, Alexander Wilkins, Zher Wen Au, Anoushka Dave and Carol Cooley for help with building plasmids and strains throughout the project; Pia Longhese for communication of results prior to publication; Ken Wolfe for discussion. This work was supported by grants from the Medical Research Council (G0701428) and Cancer Research UK (C28567/A12720) to A.B., from the Swiss National Science Foundation (31003A_17544) and European Research Council (681-630) to P.C. and from Wellcome Investigator award No.110047/Z/15/Z to A.M.C.

\section{Author contributions}

A.B. designed the study, wrote the manuscript, overviewed and contributed to execute all the genetic experiments, carried out some of the telomere length analysis and genotoxicity assays, and analysed data. E.C. and P.C. designed and performed the biochemical experiments, and edited the manuscript. A.W.O. designed the Rad50 truncations for yeast two-hybrid assays. A.M.C contributed to design the study and edited the manuscript. C.C. did the initial sequence analysis to identify the MIN motif and edited the manuscript. M.M. performed and analysed the checkpoint experiments. W.R.F. performed and analysed the NHEJ assays. C.S. performed the initial $S c$ telomere length analysis. M.A. carried out the yeast two-hybrid assays and contributed to strain construction. A.W. carried out strain construction. F.K. performed the remaining genetic experiments with some contribution from A.B.

\section{Competing interests}

The authors declare the following competing interests: C.C. is a scientific officer, cofounder and a shareholder of SyntheX, Inc. The remaining authors declare no competing interests.

\section{Additional information}

Supplementary information The online version contains supplementary material available at https://doi.org/10.1038/s41467-021-24047-2.

Correspondence and requests for materials should be addressed to A.B.

Peer review information Nature Communications thanks Lorraine Symington and other, anonymous, reviewers for their contributions to the peer review of this work.

Reprints and permission information is available at http://www.nature.com/reprints

Publisher's note Springer Nature remains neutral with regard to jurisdictional claims in published maps and institutional affiliations.

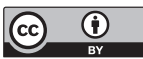

Open Access This article is licensed under a Creative Commons Attribution 4.0 International License, which permits use, sharing, adaptation, distribution and reproduction in any medium or format, as long as you give appropriate credit to the original author(s) and the source, provide a link to the Creative Commons license, and indicate if changes were made. The images or other third party material in this article are included in the article's Creative Commons license, unless indicated otherwise in a credit line to the material. If material is not included in the article's Creative Commons license and your intended use is not permitted by statutory regulation or exceeds the permitted use, you will need to obtain permission directly from the copyright holder. To view a copy of this license, visit http://creativecommons.org/ licenses/by/4.0/.

(c) The Author(s) 2021 